\title{
A Case Study on TBM Cutterhead Temperature Monitoring and Mud Cake Formation Discrimination Method
}

Jie Fu

Central South University

Yimin Xia ( $\nabla$ xiaymj@csu.edu.cn )

Central South University

Hao Lan

Hunan Normal University

Dun Wu

Central South University

Laikuang lin

Central South University

\section{Research Article}

Keywords: TBM, cutterhead, monitoring system, mud cake discrimination

Posted Date: June 3rd, 2021

DOI: https://doi.org/10.21203/rs.3.rs-579169/v1

License: (9) This work is licensed under a Creative Commons Attribution 4.0 International License. Read Full License 


\title{
A Case Study on TBM Cutterhead temperature monitoring and Mud Cake Formation Discrimination Method
}

\author{
Jie Fu ${ }^{\mathrm{a}, \mathrm{b}}$, Yimin $\mathrm{Xia}^{\mathrm{a}, \mathrm{b}}{ }^{*}$, Hao Lan ${ }^{\mathrm{c}}$, Dun $\mathrm{Wu}$ a,b, Laikuang lin ${ }^{\mathrm{a}, \mathrm{b}}$ * \\ a. College of Mechanical and Electrical Engineering, Central South University, Changsha 410083, \\ Hunan, People's Republic of China \\ b. State Key Laboratory of High Performance Complex Manufacturing, Central South University, \\ Changsha 410083, Hunan, People's Republic of China; \\ c. College of Engineering and Design, Hunan Normal University, Changsha 410081, China; \\ *Corresponding author: e-mail address: xiaymj@csu.edu.cn. Tel.: +86 073188876926. \\ *Corresponding author: e-mail address: linlaikuang34@163.com. Tel.: +86 073188876926.
}

\begin{abstract}
The mud cake is easily formed during the tunnel boring machine (TBM) excavation in clay soils or rocks containing clay minerals. Mud cake will lead to soil disturbance, clogging cutterhead and even affect the construction efficiency and personnel safety. In this study, a mud cake formation discrimination method based on cutterhead temperature was proposed. An online monitoring system was designed and installed on the slurry shield TBM. The results show that: (a) the cutterhead temperature data can be reliably detected and transmitted by the system; (b) in a tunneling ring, the temperature at some positions of the cutterhead will increase first and then decrease; (c) during the field test, the temperature variation is around $2.5^{\circ} \mathrm{C}$ under the normal condition, but the temperature variation will increase more than $50^{\circ} \mathrm{C}$ due to the mud cake or geological change; (d) compared with the cooling rate, mud cake formation can be accurately discriminated.
\end{abstract}

\section{Keywords}

TBM, cutterhead, monitoring system, mud cake discrimination

\section{Introduction}

Tunnel Boring Machines (TBMs) have been widely used in urban tunnel projects for roads, subways, and underground pipe corridors as the result of their high efficiency (Rostami 2016, Samaei et al. 2020, Sun et al. 2018). However, the complex and varied geological conditions could directly affect the 
tunneling efficiency of TBMs. Earth pressure balance (EPB) shield TBMs and slurry shield TBMs are mainly used for soft soil. The stability of the cutting surface of these TBMs needs to be ensured by the support fluid. As the viscosity of the support fluid and soil increases, the mud will stick to the surface of the tip and form a mud cake as shown in Fig 1. When the mud cake expands, the excavation performance of fluid-supported TBMs will be severely affected such as the blocked cutterhead and the decreased cutter penetration. The thrust and torque of TBM, as well as the temperature of the cutterhead, will rise sharply (Naghadehi et al. 2019, De Oliveira et al, 2019). In an EPB shield TBM project of Beijing Metro, the cutterhead temperature has risen more than $60^{\circ} \mathrm{C}$ after the formation of mud cake. The high temperature will harden the mud cake and make it difficult to remove (Wang et al. 2019, Li et al. 2014). If the mud cakes could not be eliminated in time, soil disturbances will be increased and lead to the collapse of tunnel face, ground subsidence, and other engineering accidents. More seriously, operators who are required to clean mud cake by entering the cutterhead will face greater safety hazards (Bilgin 2016, Budach et al. 2009). Therefore, finding and cleaning up mud cake in time will help to improve TBM construction efficiency.
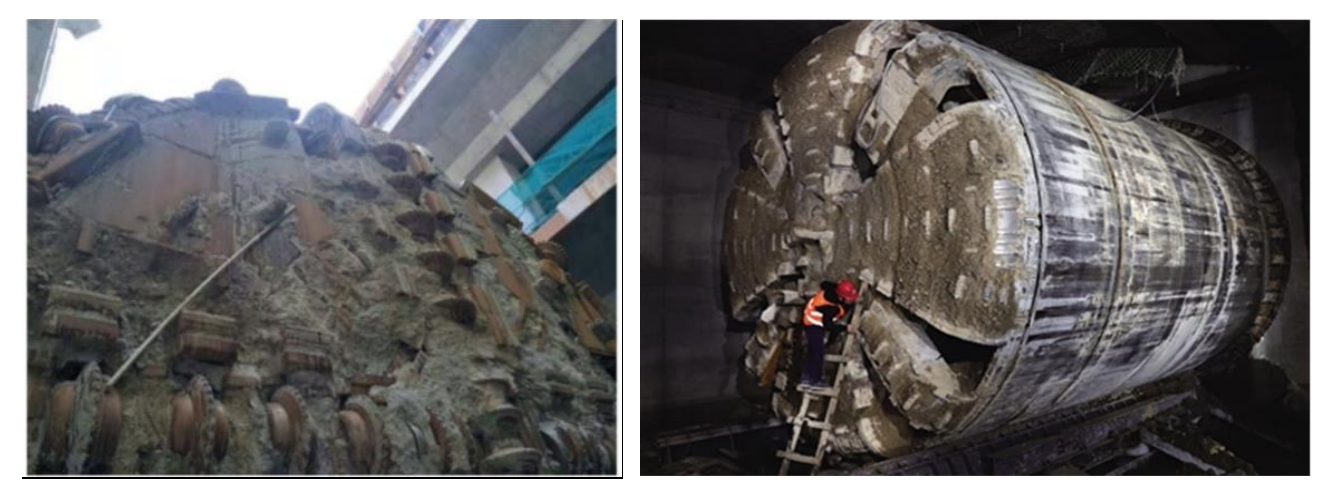

Fig 1. mud cake at the cutterhead

Many scholars started from the cause of clogging and studied the influencing factors in the soft soil layer that easily lead to mud cake or clogging. In particular, clogging of cutterhead is mainly affected by the open area and the viscous soil material (Burbaum 2009). Hollmann(2013) and Thewes(2016) suggested that the solid rock could also cause the cutterhead clogging. They summarized the effects associated with the clogging tendency of soils and proposed a new test to assess the clogging risk of rocks containing clay minerals. Feinendegen et al. (2010) developed a conical pull-out test to detect (and quantify) the adhesion/clogging tendency of existing rocks or soils in the early stages of the project and to quantify them as much as possible. Zumsteg et al. (2012) investigated the effects of clay mineralogy 
and composition of the support fluids on cutterhead clogging and clay paste. A classification scheme for clogging potential based on the newly defined plugging potential of adhesion parameters has been proposed (Feinendegen et al. 2011). De Oliveira (2019) presented a combined laboratory routine to characterize and evaluate the clogging and fluidity of soils. The above studies analyzed the causes and trends of cutterhead clogging. However, due to the lack of effective monitoring methods, there were still few researches on the mud cake which forms in the early stage of clogging.

Meanwhile, some methods of reducing or eliminating mud cakes and clogging have been proposed. Milligan et al (2000) pointed out that increasing the total surface negative charge on solid particles was suitable for viscous soils. M. Thewes et al. $(2005,2014)$ proposed a series of methods to prevent and relieve clogging and applied them to EPB shield TBMs. Zumsteg et al $(2013,2016)$ quantified and explained the limited efficiency of existing conditioning chemicals, by which an enhanced interaction mechanism is also proposed to reduce soil viscosity. Zhang (2016) proposed a block-classification method for assessing block removability and the possibility of cutterhead clogging, which can be used to avoid clogging during TBMs tunneling. Due to the complexity and variety of geological conditions, the mud modifier cannot be adapted to all types of geology. Attempting to reduce this risk by adding anticlogging chemicals could not always produce the desired results. Subsequently, there is an urgent need to monitor the formation of mud cakes in real-time to ensure timely detection and effective treatment.

At present, most of the monitoring methods for TBM cutting temperature were only applicable to the laboratory testing. Lv (2012) and Zhang (2017) used the infrared thermal imager to monitor the temperature during the cutting test of cutter and disc cutter. Some scholars tried to monitor the temperature of the cutting tools during TBM working. Sahinoglu et al. (2020) used a handy infrared thermometer to monitor the temperature while the TBM was already in operation or when it was stopped to open the excavation chamber cover. This measurement method cannot get the continuous temperature changes during the excavation, while only the temperature value at a certain moment can be obtained. Ji et al. (2019) invited a cutter temperature monitoring system, punching a hole in the cutter for temperature monitoring. However, the temperature sampling interval was relatively long and the sampling data was inadequate. In addition, more researchers paid attention to the cutting performance of the disc cutters. For instance, the wear and speed of real-time monitoring device has been successfully tested in the laboratory tests and used in a Chinese TBM project (Huang et al. 2018, Sun et al. 2016, Lan et al. 
2016,2019). The Mobydic system which was based on the serpentine manipulator and camera for monitoring TBM cutterhead has been used in Hong Kong (Sahi et al. 2013, Combe et al. 2013). In a word, few researchers paid attention to the monitoring of cutterhead temperature, and there was little data to analyze the formation of mud cake by temperature. But the existing monitoring system can be used as the basis for the design of the cutterhead temperature monitoring system.

In order to find the mud cake as early as possible, based on the characteristics that the cutterhead temperature will rise during the formation of the mud cake, a mud cake discrimination method is proposed in this paper. In addition, the online monitoring system of the cutterhead temperature was designed as well. The system was applied and verified in the large-diameter slurry shield TBM project. In a word, the online monitoring system could realize the discrimination of mud cake formation without entering the working surface, which would efficiently improve construction efficiency, saving construction cost and personnel safety.

\section{Principle of the mud cake discrimination}

During the tunneling of TBM, the cutterhead performs a compound motion of rotation and propulsion through the drive of the main drive and propulsion system. An entire tunneling ring of TBM tunneling consists of two stages: excavation and segment assembly. The cutterhead and cutters in contact with the soil will raise the temperature of the cutterhead during the excavation phase. When the TBM is assembling segments, the temperature of cutterhead will gradually decrease because of the natural heat dissipation of the soil or the muddy water circulation in the slurry shield TBMs. However, after the mud cake is formed, the temperature of cutterhead will increase sharply during excavation, which can be regarded as an important indicator to discriminate the mud cake formation.

If there is a boulder, bedrock protrusions, or stratum changes to harder during the tunneling, the thrust and torque of the TBM will also increase. More heat is released during the process of cutting the rock, and the temperature of the cutterhead suddenly rises. Therefore, the abnormal increase in the temperature of the cutterhead may be due to not only the formation of mud cake but also the geological changes. Focusing only on the maximum temperature value change of the cutterhead does not accurately discriminate whether a mud cake is formed. As shown in Fig 2, When the mud cake is not formed, the heat generated by friction on the cutterhead surface will directly flow into the tunneling stratum and dissipate. But the mud cake will cover the surface of the cutterhead after it is formed. At this time, the 
mud cake will separate the cutterhead from the tunneling stratum, and the heat preservation of mud cake shall be generated to slow down the heat dissipate. Therefore, heat dissipation rate of cutterhead is another important indicator to judge whether mud cake is formed or not. During the segment assembly stage, the temperature of cutterhead will decrease gradually because there is no friction heat. In order to distinguish the formation of mud cake and the geological changes, the temperature cooling rate of the cutterhead in the stage of segment assembly is used for discriminating the mud cake formation. The cooling rate of the cutterhead can be expressed by the following equation:

$$
k=\left|\frac{\Delta T}{\Delta t}\right|=\left|\frac{T_{0}-T_{1}}{t_{0}-t_{1}}\right|
$$

where $T_{0}$ represents initial temperature, $T_{l}$ represents final temperature, $t_{0}$ represents initial time, $t_{l}$ represents final time, $k$ represents the cooling rate of the cutterhead with the unit of ${ }^{\circ} \mathrm{C} / \mathrm{min}$.
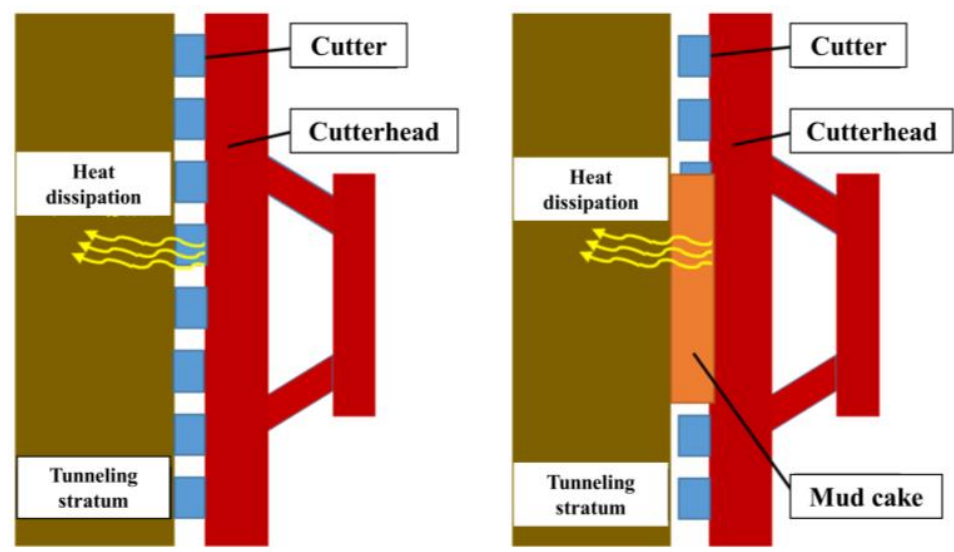

Fig 2. comparison of heat dissipation of cutterhead before and after mud cake formation

The maximum cutterhead temperature $\left(T_{\max }\right)$ and the cooling rate $(k)$ of each tunneling ring should be recorded. After analyzing temperature results, the abnormal conditions of the cutterhead could be discovered. It can be determined that mud cake has been formed when $T_{\max }$ suddenly increases and $k$ gradually decreases. In addition, the type of TBM, the geological condition, and the structure of the cutterhead could all affect the temperature of the cutterhead during the excavation. Therefore, it is necessary to rely on the temperature data, which is collected in the same working conditions for analysis.

\section{Design and development of the monitoring system}

\subsection{Design of the monitoring system}

To accurately monitor the temperature, the digital temperature sensor is applied to the monitoring system, where the data acquisition device can directly read the temperature data. Since the sensor is mounted on a rotating cutterhead, it is difficult for the sensor to transmit the signal to the host computer 
at the rear through the signal line. Moreover, the signal could be easily disturbed and the transmission is unstable when applying a rotary joint as the signal transmission. Nowadays, wireless monitoring has been applied in many projects as an important means of TBM cutterhead inspection (Sun et al. 2016, Lan et al. 2019). Therefore, the wireless transmission technology is applied to the temperature monitoring system for cutterhead, which is to obtain a real-time signal from the temperature sensor in this study. The transmitted temperature data is displayed on a self-developed PC software platform. Moreover, the constitution diagram of the entire monitoring system is shown in Fig 3. During the actual installation, it is also necessary to consider the surrounding environment, signal shielding, and other issues. The structure of the sensor, the mounting location and the layout of the transmission line are designed according to the actual situation on site, respectively.

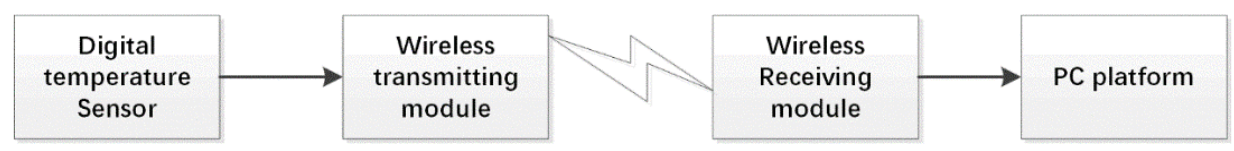

Fig 3. Constitution diagram of the mud cake monitor system for TBM cutterhead

\subsection{Development of the monitoring system}

In this study, 433-LORA wireless communication modules with MSP430 CPU and digital temperature sensors are employed. The whole temperature monitoring system for cutterhead consists of online temperature monitoring sensors, a wireless receiving system and a laptop with the self-developed software platform. In addition, each sensor has a specific address when transmitting signals. All sensors share a receiving device for signal transmission, and digital signal processing is carried out by the selfdeveloped software. The online temperature monitoring sensor includes five digital temperature sensors, one $3.8 \mathrm{~V}$ battery and one wireless transmitting module. All components are waterproofed by the sealant. According to the preliminary investigation of the Hangzhou Wangjiang Road Crossing River Tunnel in China, the temperature of the cutterhead is usually $20-30^{\circ} \mathrm{C}$ during the tunneling process. DS18B20 digital temperature sensor with a range of $-55^{\circ} \mathrm{C}-120^{\circ} \mathrm{C}$ is applied to the monitoring system and the integrated sensor module is illustrated in Fig 4. 


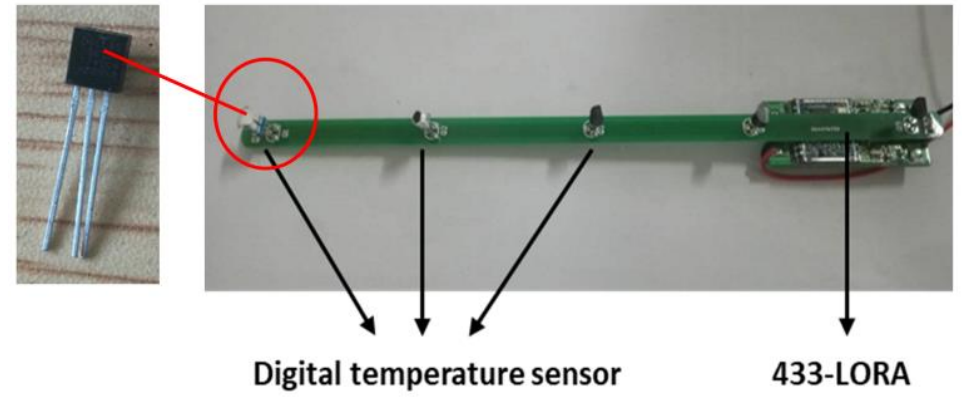

Fig 4. The integrated sensor module

The sensor module shown in Fig 5(a) is pre-mounted into the designed aluminium alloy plate, which is to ensure the stability and convenience of the sensor installation. To prevent sensor failure by the wet environment, the electronic components are sealed with sealant during installation. The bosses designed in the module are not only easy to location during installation, but also allow the sensor to contact with the cutterhead for a more accurate temperature measurement. The online temperature monitoring sensor base shown in Fig 5(b) is welded to the back of the cutterhead. Next, the sensor body is mounted on the sensor base by bolts and coated with thermal silica gel on the contact surface for the heat conduction.
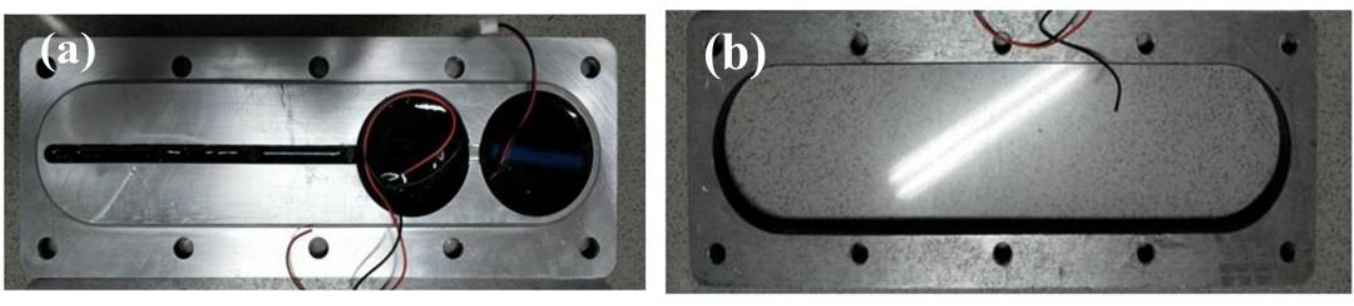

Fig 5. Sensor structure installed in the field: (a) Sensor body, (b) Sensor base

\section{Field test}

\subsection{Project introduction}

The monitoring system is applied in Hangzhou Wangjiang Road Crossing River Tunnel in Zhejiang Province of China. The tunnel crosses Qiantang River from south to north, and project location is indicated in Fig 6. Specifically, the tunnel is endowed with the length of $1835.84 \mathrm{~m}$, which passes through the silty clay and silty sand layer. Therefore, mud cake of the cutterhead might be formed during the excavation process. The construction equipment is a large-diameter slurry shield TBM, and construction company is China Railway 14th Bureau Group Shield Engineering Co., Ltd. It is equipped with an $11.64 \mathrm{~m}$ atmospheric cutterhead with the diameter of $11.64 \mathrm{~m}$. The geological conditions of the construction by TBM are shown in Table 1 . 


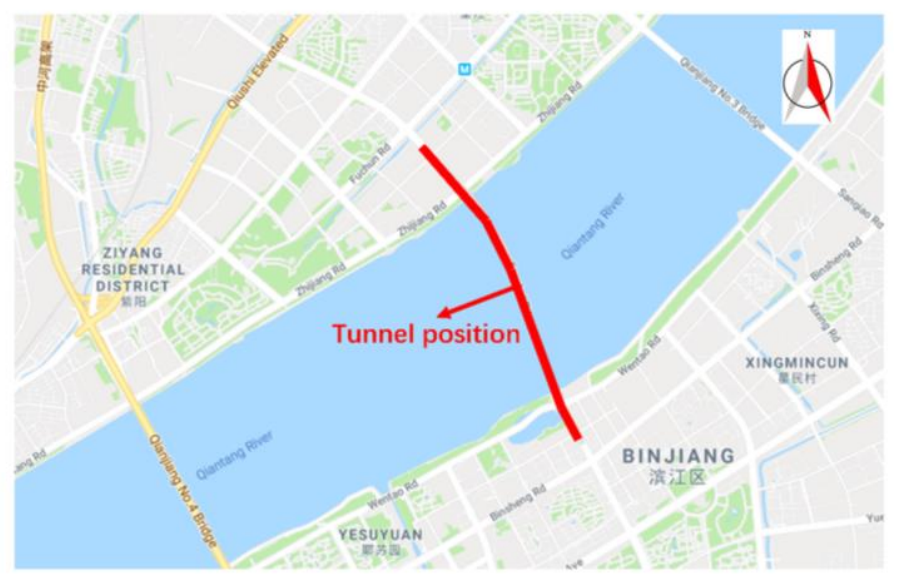

Fig 6. The location of field test

Table 1. Geological conditions of excavation strata

\begin{tabular}{cc}
\hline Exploration distance $(\mathrm{m})$ & Excavation geology types \\
\hline ZK1+0 ZK1+346 & Silty sand, Silty clay, Silt \\
ZK1+346 ZK1+545 & Silty clay, Silt, Sand \\
ZK1+545 ZK1+810 & Sandy silty clay, Silty clay \\
ZK1+810 ZK2+005 & Mucky clay, Silty clay \\
ZK2+005 ZK2+335 & Silty clay, Gravel \\
ZK2 $+335 \sim Z K 2+540$ & Mucky clay, Silty clay \\
ZK2 $+540 \sim Z K 2+840$ & Silty sand, Silt, Silty clay \\
\hline
\end{tabular}

Fig 7 shows the cutterhead and cutter. In particular, the cutterhead consists of the cutter-changing chamber and one centre cone which can change the cutter under conventional atmospheric pressure. Separated by the gates, the interiors of cutterhead are hollow. The operators can enter the cutter-changing chamber and centre cone directly. The temperature sensor is mounted on the back of the centre cone and detects the real-time temperature. The field installation is designed to validate the reliability of the monitor system as well as the accuracy of cutterhead temperature during the TBM excavation. 


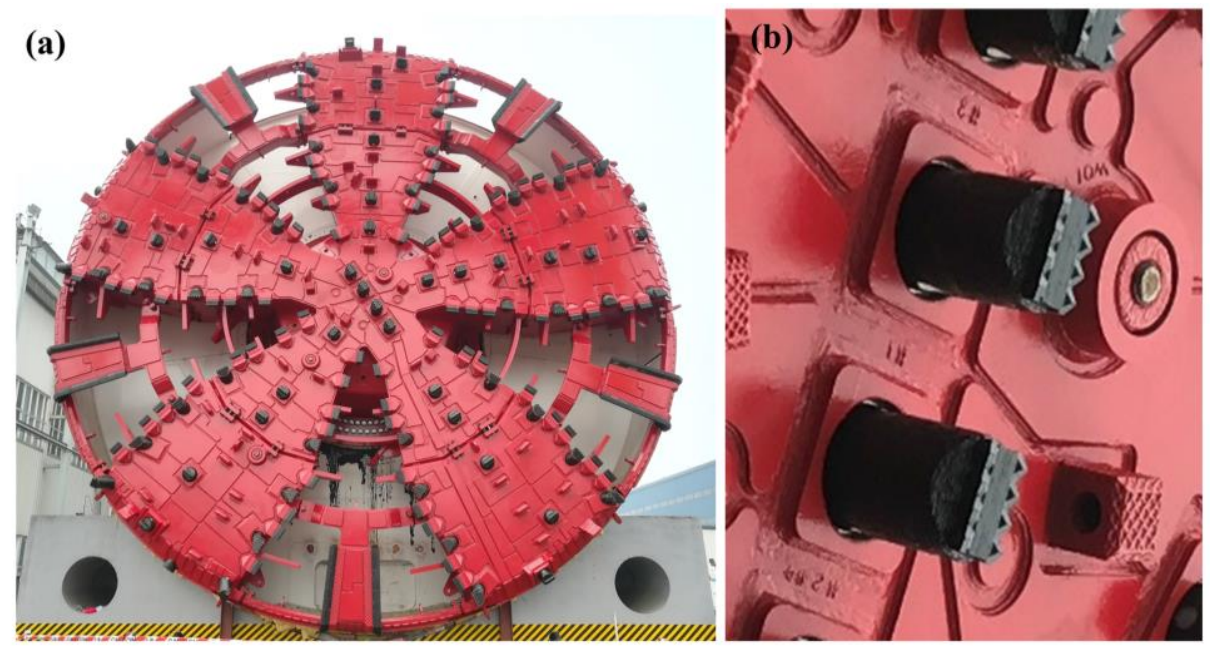

Fig 7. Cutterhead and cutter of the large-diameter slurry TBM: (a) cutterhead, (b) Normal pressure replaceable cutters.

\subsection{Installation of the monitoring system}

As shown in Fig 8, five sensors were mounted in the cutterhead center where mud cakes are most likely to be formed. To monitor the temperature online, the manhole in the excavation chamber was opened to avoid any screen effect on the wireless-signal transmission from the sensor. The receiving module was kept on a transport rack and connected to the monitor laptop which was installed in the main control room through cables as shown in Fig 9. The cutterhead structure and signal transmission diagram are shown in Fig 10. The signal between the sensor and the receiving device is transmitted wirelessly, while the signal between the receiving device and the computer is transmitted by cable. The signal transmission is shown by the orange arrow line in Fig 10. Therefore, the rotation of the cutterhead would not affect the signal transmission.
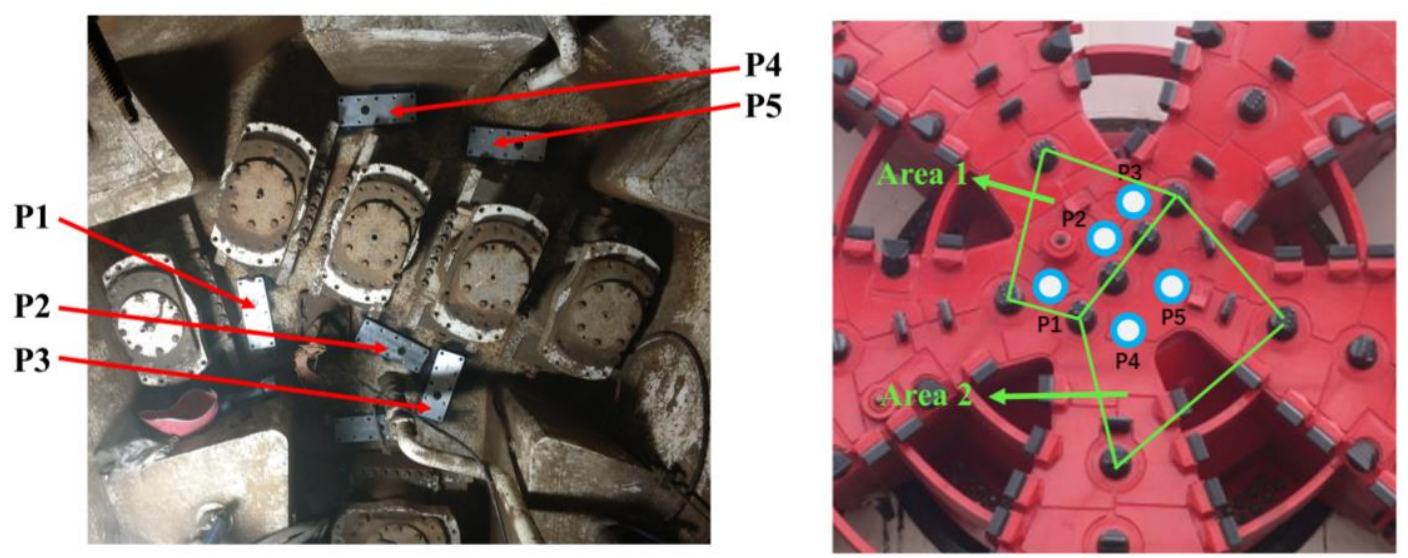

Fig 8. Images of sensors installed on the cutterhead 


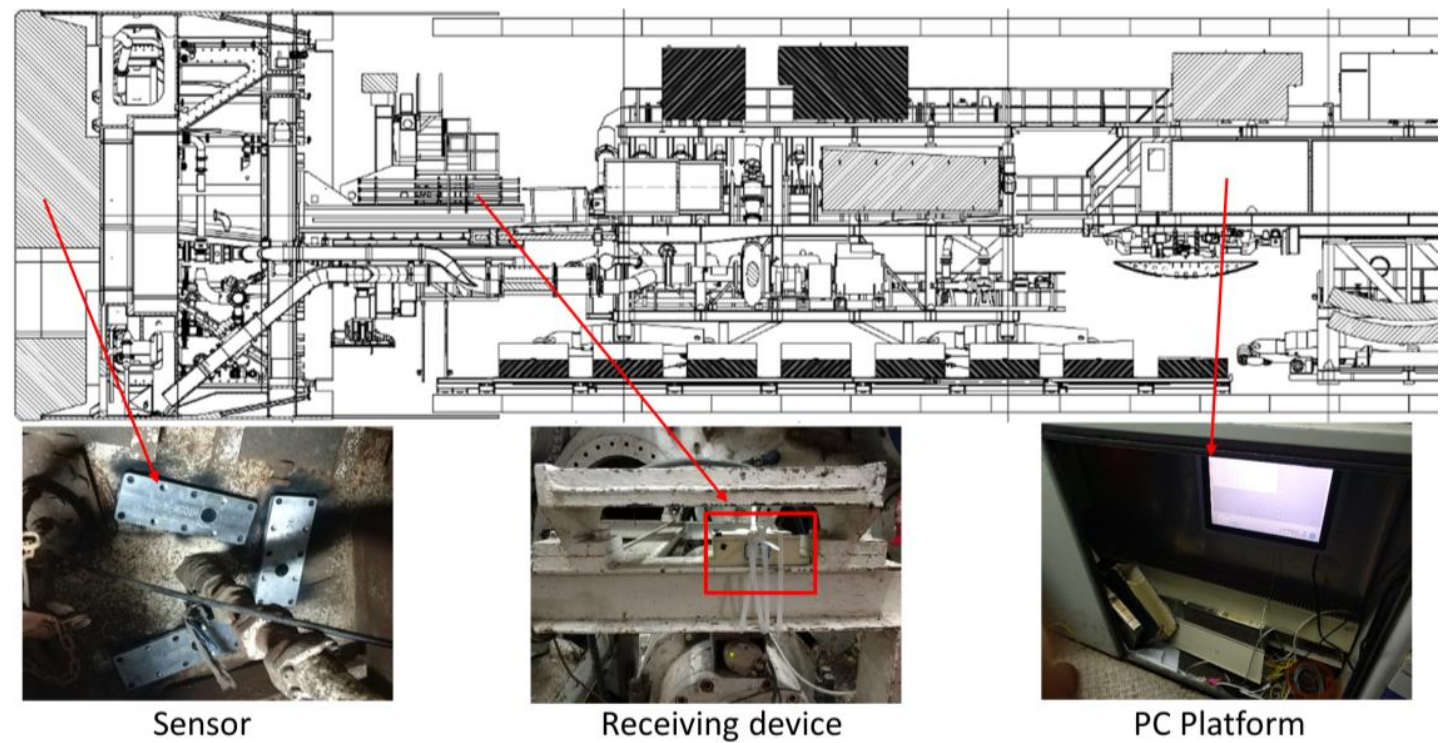

Fig 9. Installation position of monitoring system
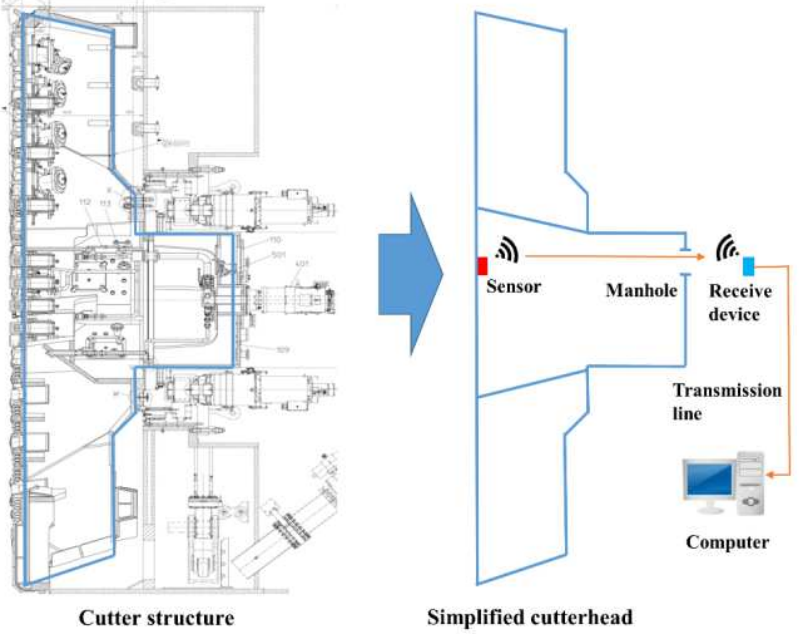

Fig 10. Cutterhead structure and signal transmission diagram

A self-developed software was employed to collect and display the sensing data when the TBM was digging and thrusting. Fig 11 shows the software interface for temperature measurements where seven parameters of the system (including, serial number, temperature value, and device voltage value) are displayed in real-time. To increase the signal-to-noise (SN) level, the average of 5 temperature points measured by each sensor is recorded at one time. In addition to temperature measurements, the real-time system can monitor the power of each sensor to avoid battery exhaustion. 


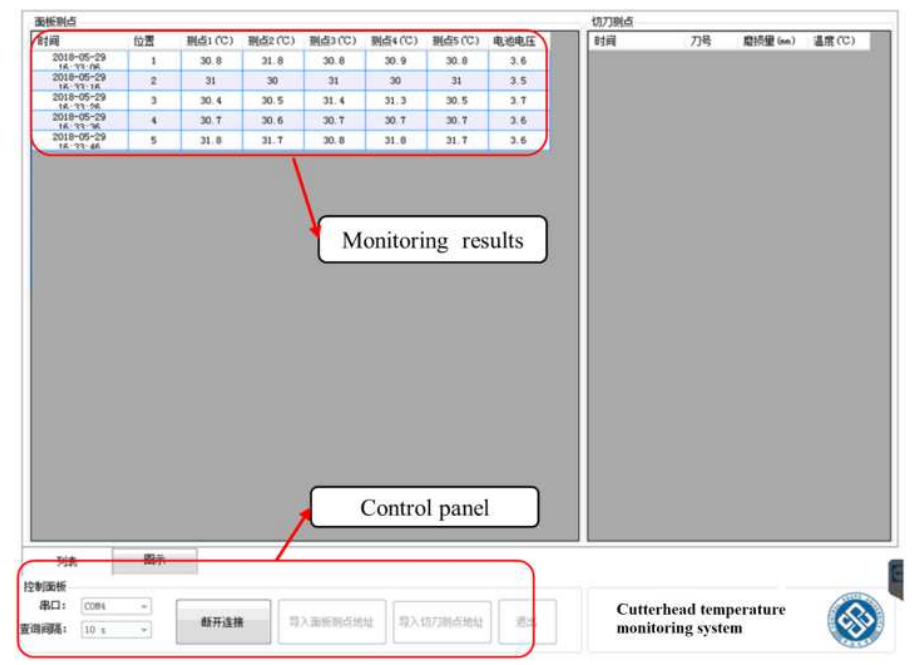

Fig 11. Self-developed temperature monitoring software

\subsection{Temperature data analysis}

The temperature monitoring system of cutterhead was tested in the slurry shield TBM construction site in Hangzhou from April to June 2018. After installation of the entire monitoring system, The realtime temperature change of the cutterhead could be detected with good stability by the monitoring system.

\subsubsection{Single ring temperature data analysis}

On $10^{\text {th }}$ April, the slurry shield TBM achieved for a tunneling of two rings with average thrusts of $52537 \mathrm{kN}$ and $55133 \mathrm{kN}$. The torque for each ring was $1896 \mathrm{kN} \cdot \mathrm{m}$ and $1760 \mathrm{kN} \cdot \mathrm{m}$, respectively. As illustrated in Fig 12, temperatures of the five test points were in the range from $22.5{ }^{\circ} \mathrm{C}$ to $24{ }^{\circ} \mathrm{C}$, which was close to the temperature of the tunnel. The temperature change of the cutterhead was within $3{ }^{\circ} \mathrm{C}$. Furthermore, temperatures of measuring points (P1, P2, P3) went up rapidly as the slurry TBM started tunneling. After around 50 minutes, the temperatures in Ring 1 and Ring 2 reached up to $25.26{ }^{\circ} \mathrm{C}$ and $25.9^{\circ} \mathrm{C}$, respectively. When the excavation process was completed, and the segment assembly began, temperatures of the three test points decreased gradually. 


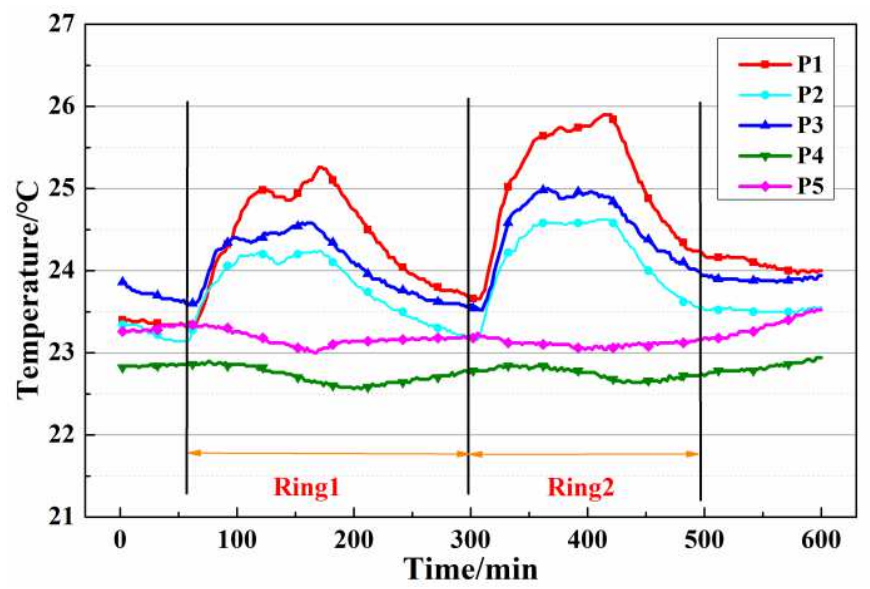

Fig 12. The temperature of cutterhead on April 10, 2018

The temperature rising at $\mathrm{P} 1, \mathrm{P} 2$ and $\mathrm{P} 3$ is caused by the heat derived from the friction between cutter and soil when the cutterhead is rotating. The working temperature of the excavation stage would be $25^{\circ} \mathrm{C}-26^{\circ} \mathrm{C}$ as shown in Fig 12 . After excavation, the mud water circulation system transports muck produced by the excavation through pipes, leading to heat dissipation and temperature decrease. On the other hand, the temperature of P4 and P5 did not change significantly. The reason for the difference of temperature change between P1 (or P2, P3) and P4 (P5) is heat dissipation. The temperature change of cutterhead is affected by many factors, including the heat produced by excavation, heat dissipation caused by slurry flow, and the ambient temperature. The slurry between the cutterhead and cutting face is squeezed into the slurry warehouse through the opening of the cutterhead. Therefore, the better fluidity of the slurry would lead to the lower temperature at the cutting surface, the temperature of the cutterhead might not change or even decrease during excavation. As shown in Fig 8, the cutters around P1, P2, and P3 easily form a closed area when excavation. It will cause slower heat dissipation of the cutterhead in this area. However, there is a cutterhead opening in the closed area formed by the cutter around P4 and P5, which contributes to a high heat dissipation rate. Hence the temperature change is not obvious, or even the opposite change law.

\subsubsection{Long-time continuous data analysis}

Long-time continuous testing of the mud cake monitor system had been carried out from April $9^{\text {th }}$ to April $19^{\text {th }}$. The stratum of the slurry shield TBM was loose silty soil and sand layer. The thrust and torque during excavation were shown in Fig 13. The thrust was between $50000 \mathrm{kN}$ and $60000 \mathrm{kN}$, and the torque fluctuated around $2000 \mathrm{kN} \cdot \mathrm{m}$. The average tunneling speed was $23 \mathrm{~mm} / \mathrm{min}$. During this time, there was no obvious change in the stratum and other excavation parameters. 
The temperature of P1, P2 and P3 test points were shown in Fig 14. It can be seen that the temperatures of the P1 P2 and P3 changed significantly for each excavating ring, while the temperature was almost stable for the TBM which is at idle. In the long-time continuous testing of the temperature monitor system, each distinct peak in the temperature change corresponds to a transition of TBM from the excavation stage to the segment assembly stage. While during the continuous tunneling, the maximum temperature of the measuring point gradually rose and reached a maximum value of around $26^{\circ} \mathrm{C}$, as shown in the 225-262 hour in Fig 14 . The increase of temperature arised from an accumulated heat generated during the continuous tunneling process, where the heat generation is faster than the heat dissipation during the segment assembly stage.
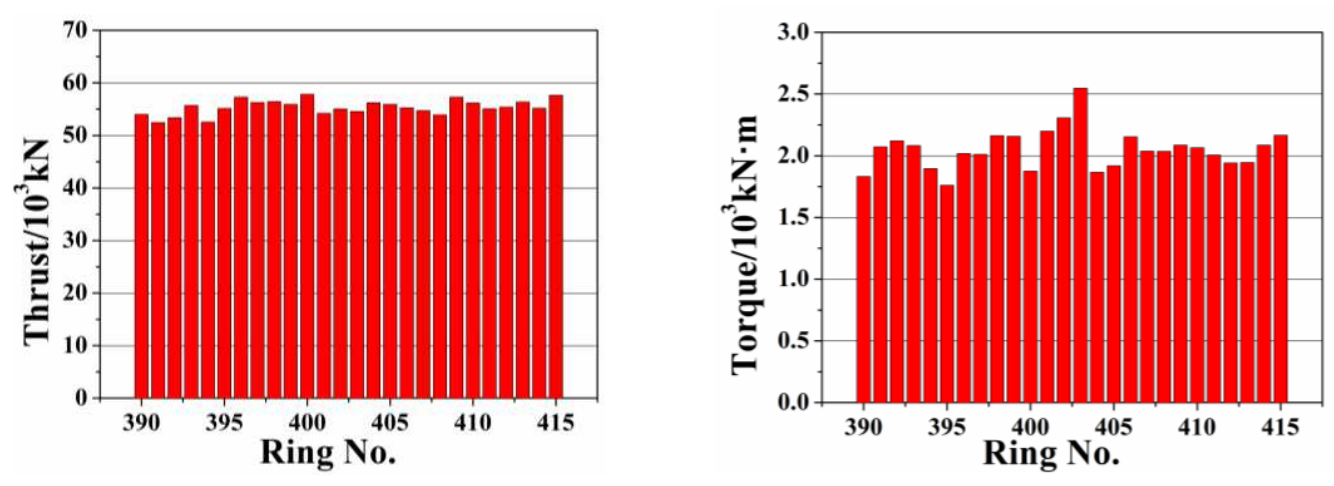

Fig 13. Thrust and Torque Statistics from April 9th to April 19th

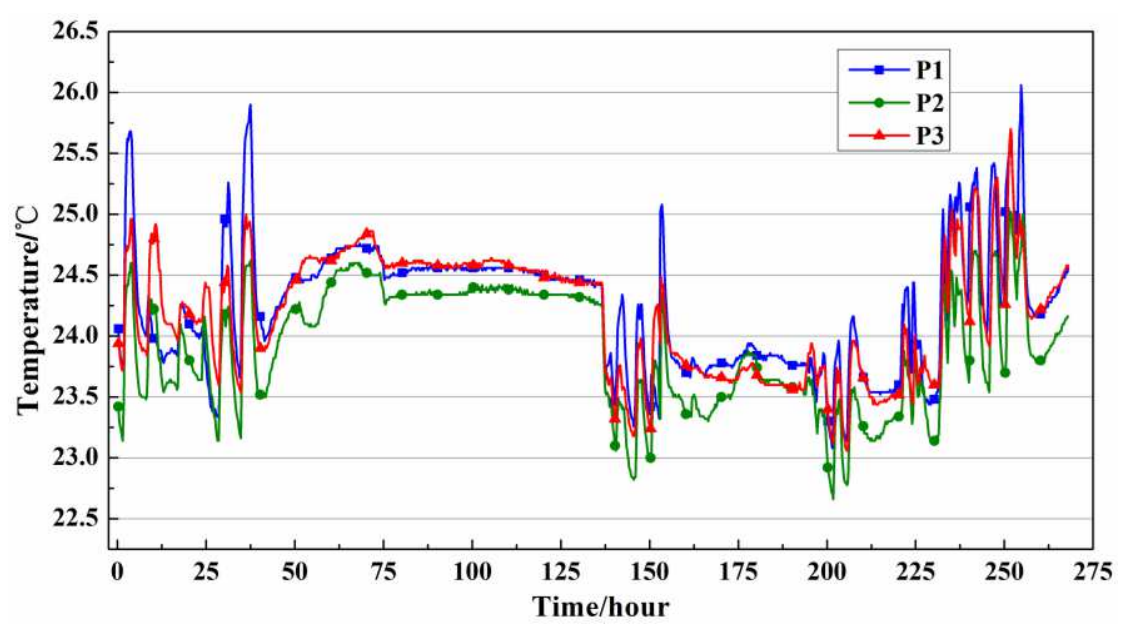

Fig 14. P1 P2 and P3 Temperature Data from April 9th to April 19th

In general, during this period, the temperature data transmission is continuous and stable. The monitoring system is not affected by the surrounding environment and can be reliably used for long-term temperature monitoring with detecting time of at least 10 days. Due to the normal state of excavation, the temperature rise of the measuring point during excavation is only $1.5-2{ }^{\circ} \mathrm{C}$. The long-term test has 
further verified the reliability of the temperature monitoring system.

\section{Discussion of abnormal temperature rise}

In the entire temperature monitoring process, we noticed two abnormal rising trends of the cutterhead temperature. The curves of these two abnormal temperature changes were shown in the Fig 15. The temperature went up to about $75^{\circ} \mathrm{C}$ which was twice as those of the normal tunneling rings. Since the sensor was mounted on the backside of the cutterhead, it was conceivable that the temperature of the front of cutterhead will be higher. Fig 16 illustrated the trend of the average thrust and torque of several tunneling rings when two temperatures rose abnormally. The thrust of the slurry shield TBM rose to $80000 \mathrm{kN}$, and the torque reached $7000 \mathrm{kN} \cdot \mathrm{m}$ simultaneously. When these tunneling parameters rose significantly, excavation speed slowed down. Therefore, it can be discriminated that the excavation stage was under an abnormal circumstance. To give a more specific clarification, further analysis of the cooling rate would be required when the slurry shield TBM is shut down.
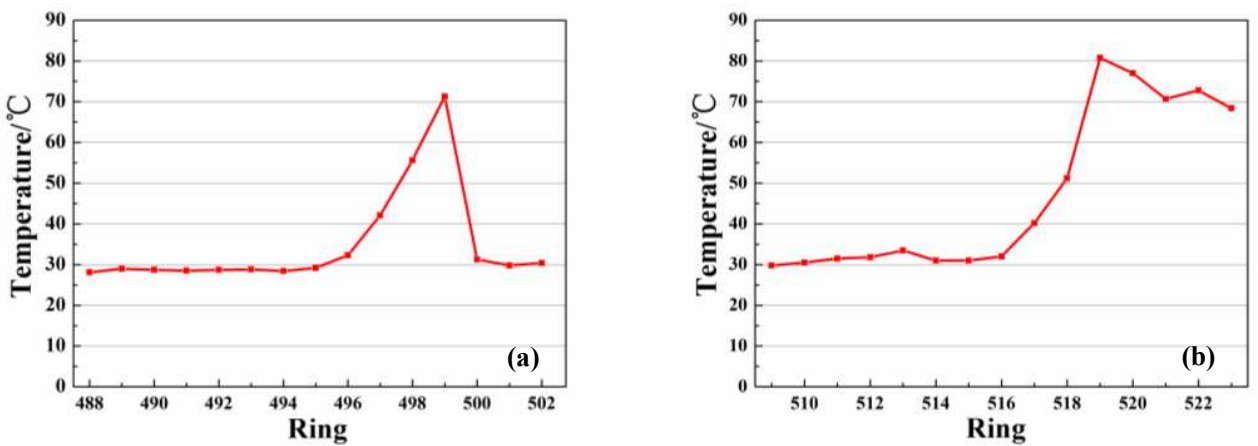

Fig 15. Temperature maximum: (a) First, (b) Second
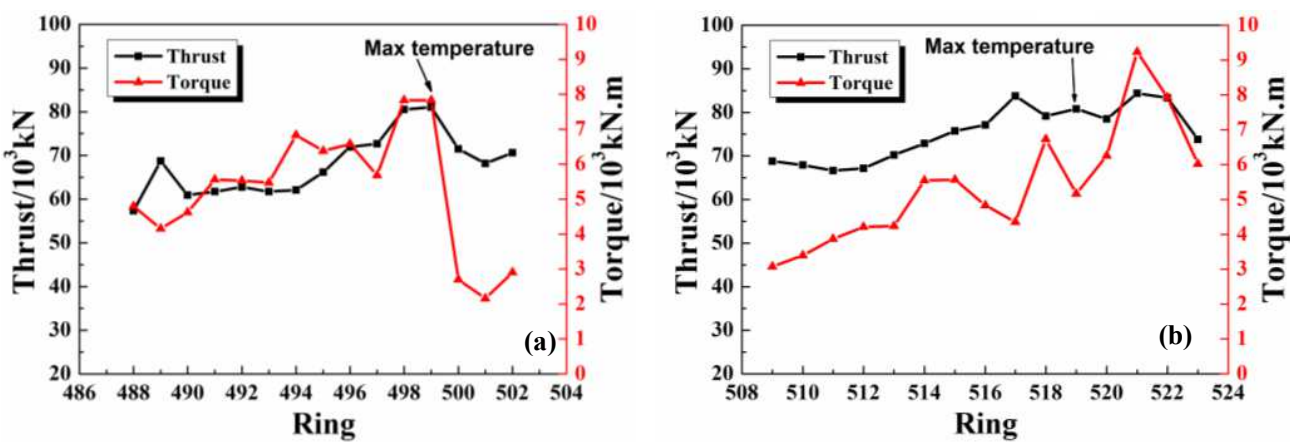

Fig 16. Average thrust and torque: (a) First, (b) Second

The rate of the heat transfer between two objects is positively correlated with their temperature difference, i.e. the greater temperature difference between two objects would lead faster heat transfer from the high temperature object to the low temperature object. Therefore, we choose the same initial temperature to analyze the cutterhead cooling process, or the difference in temperature will impact the 
cooling rate. We selected the P1 measuring point to analyse the temperature variation at the tunneling ring with the highest temperature and also the previous two tunneling rings. The ring number of the first part is $497-499$ and the second part is $517-519$. The initial temperature of the analysis is around $42{ }^{\circ} \mathrm{C}$ with the cooling time of 90 minutes. Cooling rate $k$ (Formula 1$)$ is obtained by regression analysis. The regression curve was shown in Fig 17. The temperature of the first abnormal situation dropped by 1.5 $2.5{ }^{\circ} \mathrm{C}$ in 90 minutes, and the cooling rate $k$ was below $0.03{ }^{\circ} \mathrm{C} / \mathrm{min}$ with the minimum value of only $0.0186{ }^{\circ} \mathrm{C} / \mathrm{min}$. For the second time, the temperature dropped by nearly $4{ }^{\circ} \mathrm{C}$. The average value of $k$ was about $0.0427^{\circ} \mathrm{C} / \mathrm{min}$. The first cooling rate was significantly lower than the second one. As shown in Fig 18(a), the $k$ of the three tunneling rings showed a significant downward trend for the first time. It was very likely that the mud cake was gradually developing during the excavation, and the increase in thickness would lead a more difficult heat dissipation. The second $k$ did not change significantly, as shown in Fig 18(b), where three curves were almost parallel. During the 497-499 tunneling rings, the cutterhead temperature was rising abnormally, while the cooling rate of the cutterhead was gradually decreasing. Therefore, it could be concluded that the mud cake was formed in front of the cutterhead.
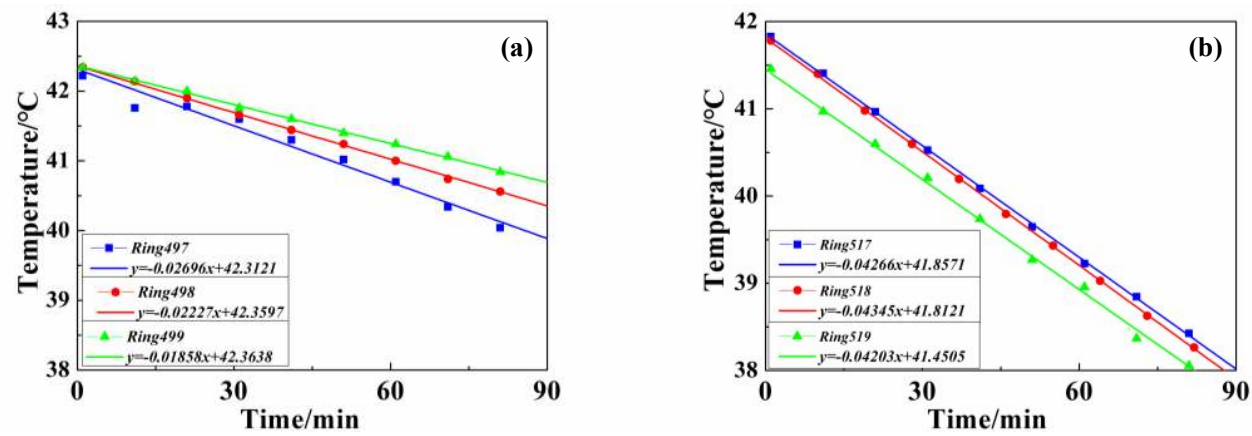

Fig 17. Temperature change regression curve: (a) First, (b)Second
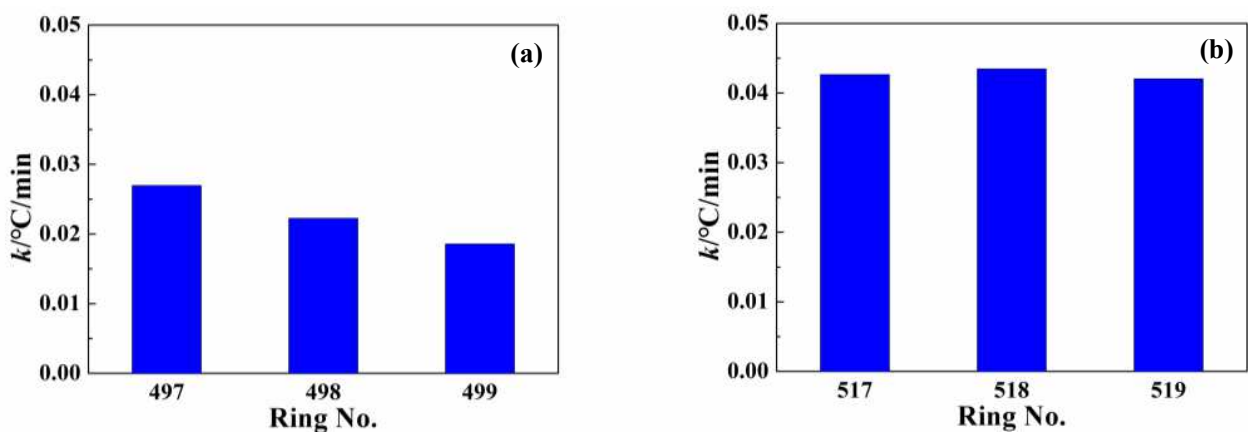

Fig 18. Cooling rate: (a) First, (b) Second

When the temperature appears abnormal for the first time, the mud cake forming was confirmed by entering the cutting face and checking. The mud piece taken out from the cutterhead was shown in Fig 19. It was a hard mud formed by the cementing of clay and gravel, which is indiscerptible in water. 
During the construction process, 1 ton of dispersant was injected into the cutterhead. To eliminate mud cakes we used the dispersing agent and rotated the cutterhead simultaneously. After that, the thrust and torque of TBM, as shown in Fig 15, in the next rings was significantly reduced, and the TBM returned to normal working when mud cake was cleaned. However, at the second time of the abnormal temperature, the addition of dispersant in front of the cutterhead failed to return the tunneling parameters and temperature normal. After checking the cutterhead, no mud cake was found. The TBM advanced 2 meters per excavation ring. The excavation distances during the second temperature abnormalities was ZK2+038m. As shown in Table 1, the excavation geology contained gravel. The strata containing gravel is harder than Silty clay, and the load will increase when excavation in gravel strata, resulting in increased heat production. That is the main reason for the increase in excavation parameters and temperature. Therefore, the geological change resulted in the temperature rose abnormally, while the cutterhead cooling rate did not change. In a word, by comparing the cooling rate, the mud cake formation and geological changes can be distinguished more accurately.
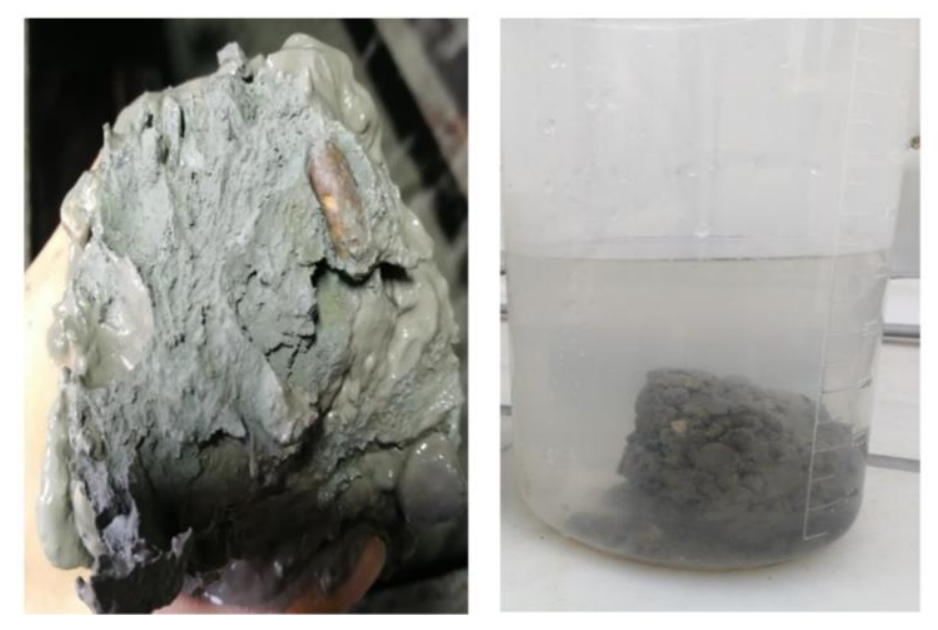

Fig 19. Mud cake sample was taken out form cutterhead

\section{Conclusion}

In this study, the discrimination method of cutterhead mud cake formation based on temperature is proposed, and a monitoring system for cutterhead temperature is developed. The monitoring system has been applied to a field test. Based on the test result, the conclusions are:

(1) Digital temperature sensors and 433-LORA wireless communication modules based on MSP430 CPU are used to measure the temperature. The real-time temperature data of the cutterhead can be viewed, analyzed and saved by the self-developed PC software. Subsequently, a series of monitoring processes 
including real-time data detection and collection, transmission, storage, management are finished.

(2) The monitoring system has been applied into the project at the Hangzhou Wangjiang Road Crossing River Tunnel in China. The results of the field test have verified the feasibility, reliability and durability. The test data did not interfere with signal shielding and cutterhead rotation. Self-developed software can control signal transmission frequency and save data in real-time.

(3) The cutterhead temperature monitoring data shows several characteristics: (a) During each tunneling ring, the cutterhead temperature will rise and fall. Under normal circumstances, the temperature difference is generally around $2.5^{\circ} \mathrm{C}$. (b) When the TBM continues to excavate, the maximum temperature of cutterhead could continuously rise. (c) When the geological hardening or mud cake formation has occurred, the cutterhead temperature rose abnormally. The maximum temperature reached to above $70{ }^{\circ} \mathrm{C}$, which was $50{ }^{\circ} \mathrm{C}$ higher than that in a normal case.

(4) The discrimination method of cutterhead mud cake has been verified at the construction site. The cooling rate was $0.04272{ }^{\circ} \mathrm{C} / \mathrm{min}$ when the formation became hard. The cooling rate of per-ring decrease when the mud cake had formed, and the minimum value was $0.01862{ }^{\circ} \mathrm{C} / \mathrm{min}$. The maximum abnomal rise of temperature in the cutterhea during excavation and the cooling rate reducing during segment assembly are important factors to discriminate mud cake formation.

The monitoring system has been applied in the large diameter slurry shield TBM and has the potential to be extended to EPB shield TBMs. By placing sensors in more locations, the entire cutterhead mud cake formation can be monitored. In the future, temperature data will be used as another important excavation parameter while evaluating the cutting performance of the TBMs.

\section{Acknowledgements}

The work was financially supported by National Key R\&D Program of China (2018YFB1306700), National Natural Science Foundation of China (51475478), Science and Technology Major Project of Hunan Province, China (2019GK1015) and the Fundamental Research Funds for The Central Universities of Central South University (2017zzts086).

\section{Conflicts of interest}

The authors declared that they have no conflicts of interest to this work. 


\section{Reference}

B. Combe, P.Moulin, 2013. Monitored disk cutters - Mobydic. Rapid Excavation and Tunneling Conference. 659-667.

C. Budach, M. Thewes, Application ranges of EPB shields in coarse ground based on laboratory research. Tunn. Undergr. Space Technol. 50 (2015) 296-304.

D.G.G. de Oliveira, M. Thewes, M.S. Diederichs, Clogging and flow assessment of cohesive soils for EPB tunnelling: Proposed laboratory tests for soil characterization, Tunn. Undergr. Space Technol. 94 (2019) 103110.

D. Lv, 2012, Friction and wear characteristics research of shield machine cutter. Central South University.

F. Hollmann, M. Thewes, Assessment method for clay clogging and disintegration of fines in mechanised tunnelling. Tunn. Undergr. Space Technol. 37 (2013) 96-106.

G. Milligan, 2000. Lubrication and Soil Conditioning in Tunnelling, Pipe Jacking and Microtunnelling: A State of the Art Review. Geotechnical Consulting Group.

H. Lan, Y. Xia, Z. Zhu, Z. Ji, J. Mao, Development of on-line rotational speed monitor system of TBM disc cutter. Tunn. Undergr. Space Technol. 57 (2016) 66-75.

H. Lan, Y. Xia, Z. Ji, J. Fu, B. Miao, Online monitoring device of disc cutter wear - Design and field test. Tunn. Undergr. Space Technol. 89 (2019) 284-294.

J. Rostami, Performance prediction of hard rock Tunnel Boring Machines (TBMs) in difficult ground, Tunn. Undergr. Space Technol. 57 (2016) 173-182.

M. Feinendegen, M. Ziegler, G. Spagnoli, T. M. Fernandez-Steeger, H. Stanjek, 2010. A new laboratory test to evaluate the problem of clogging in mechanical tunnel driving with EPB-shields. Rock Mech. Civil Environ. Eng. Taylor \& Francis Group, London, ISBN 978-0-415-58654-2 M. Feinendegen, M. Ziegler, M. Weh, G. Spagnoli, 2011. Clogging during EPB-tunnelling: Occurrence, classification and new manipulation methods. In: Proceedings ITA-AITES World Tunnel Congress, Helsinki, 767-776.

M. Samaei, M. Ranjbarnia, V. Nourani, M.Z. Naghadehi, Performance prediction of tunnel boring machine through developing high accuracy equations: A case study in adverse geological condition. Measurement. 152 (2020), 107244. 
M. Thewes, W. Burger, 2005. Clogging of TBM drives in clay - identification and mitigation of risks. In: Proceedings ITA-AITES World Tunnel Congress, Istanbul, Turkey, 737-742.

M. Thewes, F. Hollman, TBM-specific testing scheme to assess the clogging tendency of rock. Geomechanics and Tunnelling 7 (2014) 520-527. https://doi.org/10.1002/geot.201400048

M. Thewes, F. Hollmann, Assessment of clay soils and clay-rich rock for clogging of TBMs. Tunn. Undergr. Space Technol. 57 (2016) 122-128.

M.Z. Naghadehi, M. Thewes, A.A. Lavasan, Face stability analysis of mechanized shield tunneling: An objective systems approach to the problem, Engineering Geology, 262 (2019) 105307.

N. Bilgin, An appraisal of TBM performances in Turkey in difficult ground conditions and some recommendations. Tunn. Undergr. Space Technol. 57 (2016) 265-276.

N. Sahi, B. Thomas, D. Rye, 2013. TBM cutter-head instrumentation MOBYDIC systemBOUYGUES TP. World Tunnel Congress. 1304-1311.

R. Zumsteg, A. Puzrin, Stickiness and adhesion of conditioned clay pastes. Tunn. Undergr. Space Technol. 31(2012) 86-96.

R. Zumsteg, M. Plötze, A. Puzrin, Reduction of the clogging potential of clays: new chemical applications and novel quantification approaches. Géotechnique 63 (2013) 276-286.

R. Zumsteg, A. Puzrin, G. Anagnostou, Effects of slurry on stickiness of excavated clays and clogging of equipment in fluid supported excavations. Tunn. Undergr. Space Technol., 58 (2016) 197-208.

U. Burbaum, 2009. Adhäsion bindiger Böden an Werkstoffobeflächen von

Tunnelvortriebsmaschinen. Dissertation (in German). Institut für Angewandte Geowissenschaften, Technische Universität Darmstadt.

U. Sahinoglu, U. Ozer, The prediction of cutter wear from temperature measurements on TBM discs and cutting face, Arabian Journal of Geosciences, 13 (2020) 207.

W. Sun, M. Shi, C. Zhang, J. Zhao, X. Song, Dynamic load prediction of tunnel boring machine (TBM) based on heterogeneous in-situ data, Automation in Construction, 92 (2018) 23-34.

X. Huang, Q. Liu, H. Liu, P. Zhang, S. Pan, X. Zhang, J. Fang, Development and in-situ application of a real-time monitoring system for the interaction between TBM and surrounding 
rock. Tunn. Undergr. Space Technol. 81 (2018) 187-208.

X. Zhang, Y. Xia, Y. Zhang, Q. Tan, Z. Zhu, L, Lin, Experimental study on wear behaviors of TBM disc cutter ring under drying, water and seawater conditions, wear, 392 (2017) 109-117.

Z. Li, Z. Zai, K. Zhao, Causes of Mud Cake Formation on Cutter Head of Slurry Shield and Its Control Technology (in Chinese). Chinese Journal of Underground Space and Engineering, 2014 (S2) 1866-1871.

Z. Ji, Y. Xia, H. Lan, M. Yang, L, Lin, Cutterhead mud-caking detection method and application based on cutter wear and temperature measurement. Journal of Advanced Mechanical Design Systems and Manufacturing, 13 (2019) 19-00323.

Z. Sun, D. Li, J. Zhang, Wireless real-time disc cutter wear monitoring system for composite shield machine (in Chinese). tunnel construction 36 (2016) 485-489.

Z. Wang, Z. Dong, Y. Jiang, L. Dong, Y. Xiong, J. Yang, Formation Mechanism and Treatment Measures of Special Mud Cake for Shield Tunnelling in Sandy Cobble Strata (in Chinese). Modern Tunnelling Technology, 56 (2019) 175-181.

Z. Zhang, TBM-block interaction during TBM tunneling in rock masses: block classification and identification. International Journal of Geomechanics, 17 (2016) E4016001. 
Figures
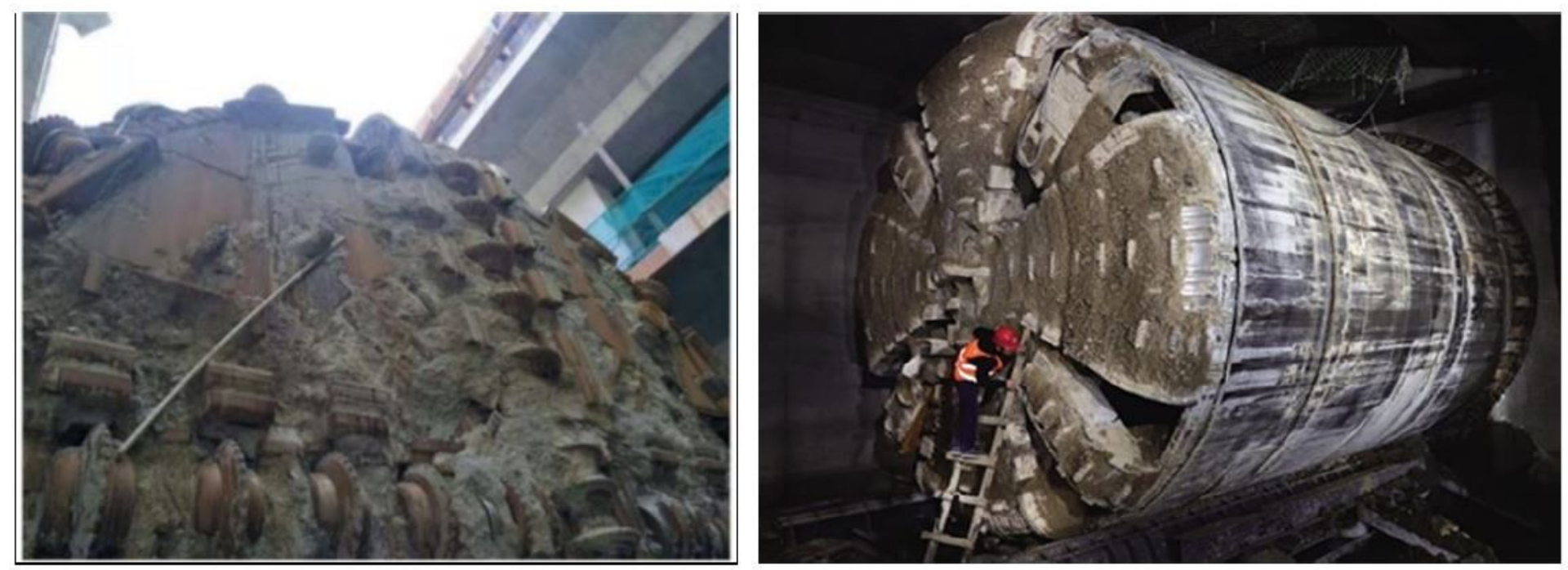

Figure 1

mud cake at the cutterhead
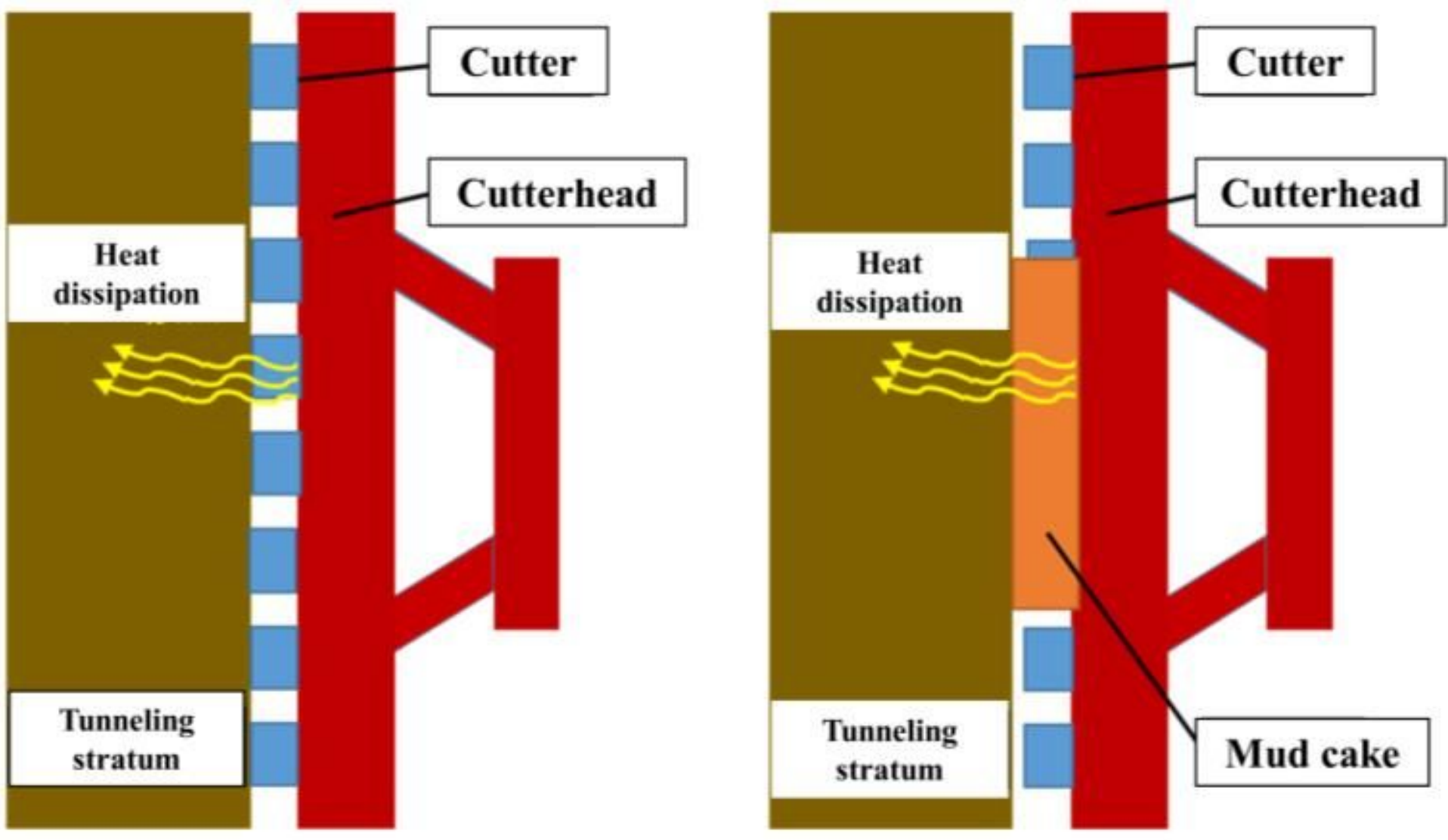

Figure 2

comparison of heat dissipation of cutterhead before and after mud cake formation 


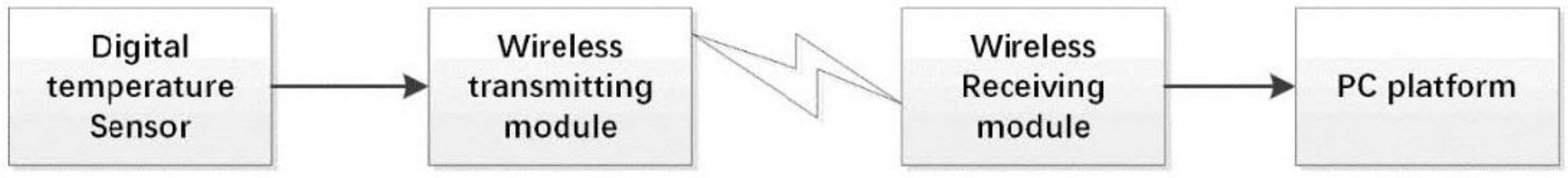

Figure 3

Constitution diagram of the mud cake monitor system for TBM cutterhead

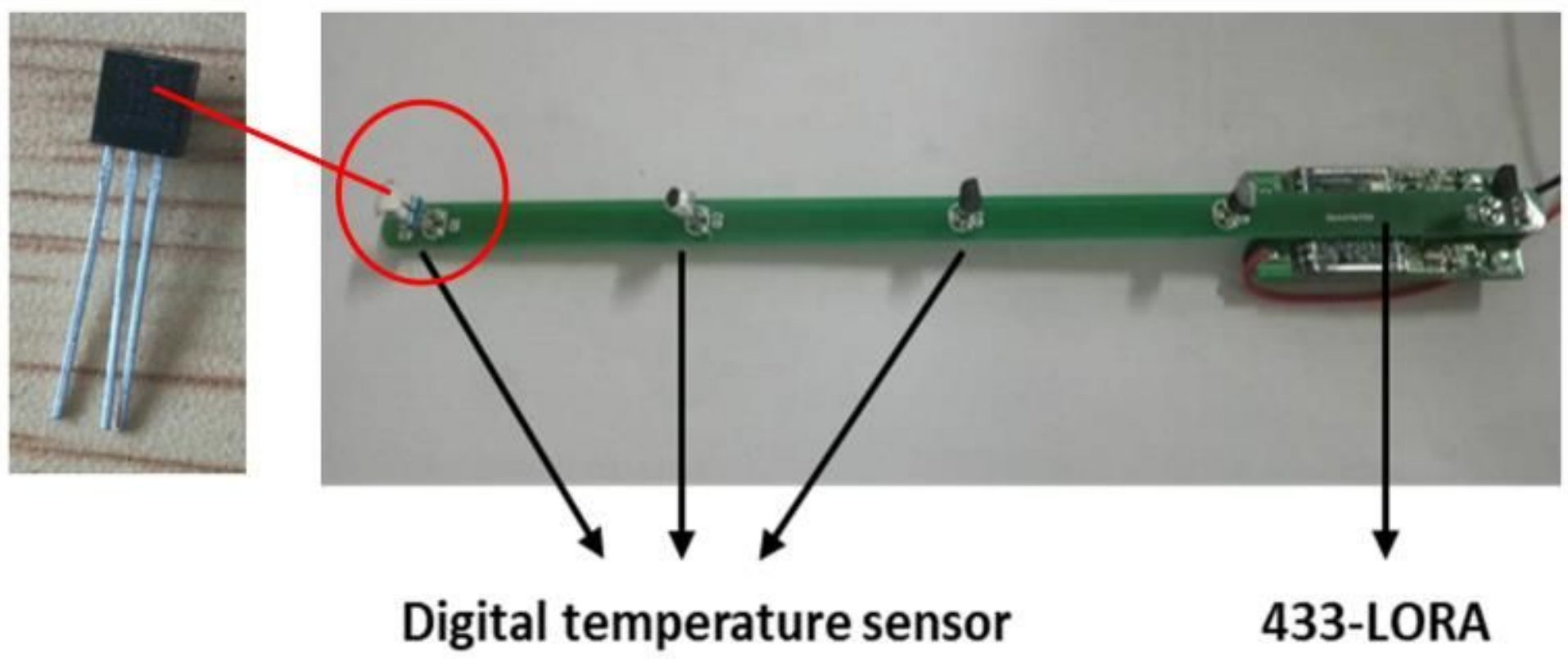

Figure 4

The integrated sensor module
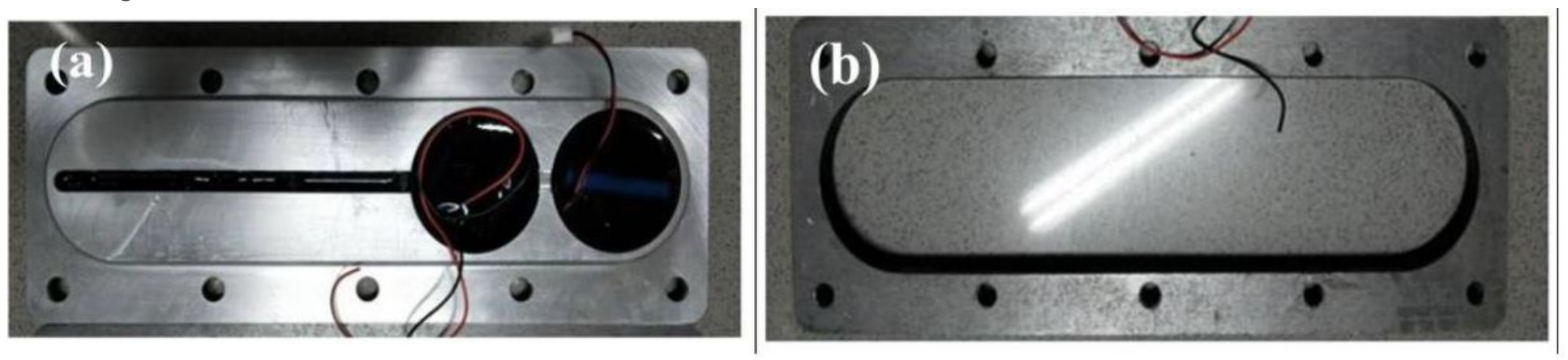

Figure 5

Sensor structure installed in the field: (a) Sensor body, (b) Sensor base 


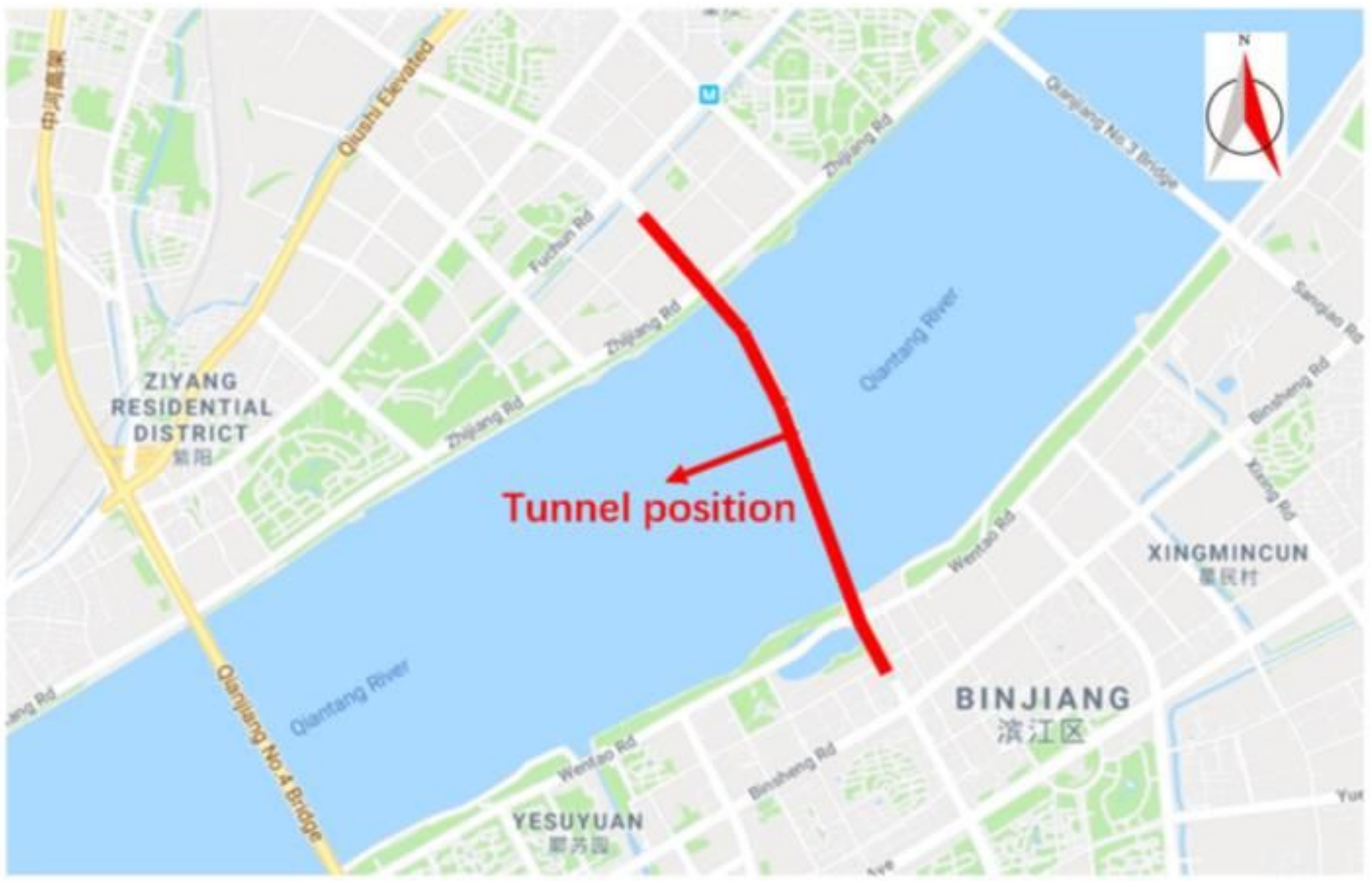

Figure 6

The location of field test. Note: The designations employed and the presentation of the material on this map do not imply the expression of any opinion whatsoever on the part of Research Square concerning the legal status of any country, territory, city or area or of its authorities, or concerning the delimitation of its frontiers or boundaries. This map has been provided by the authors. 

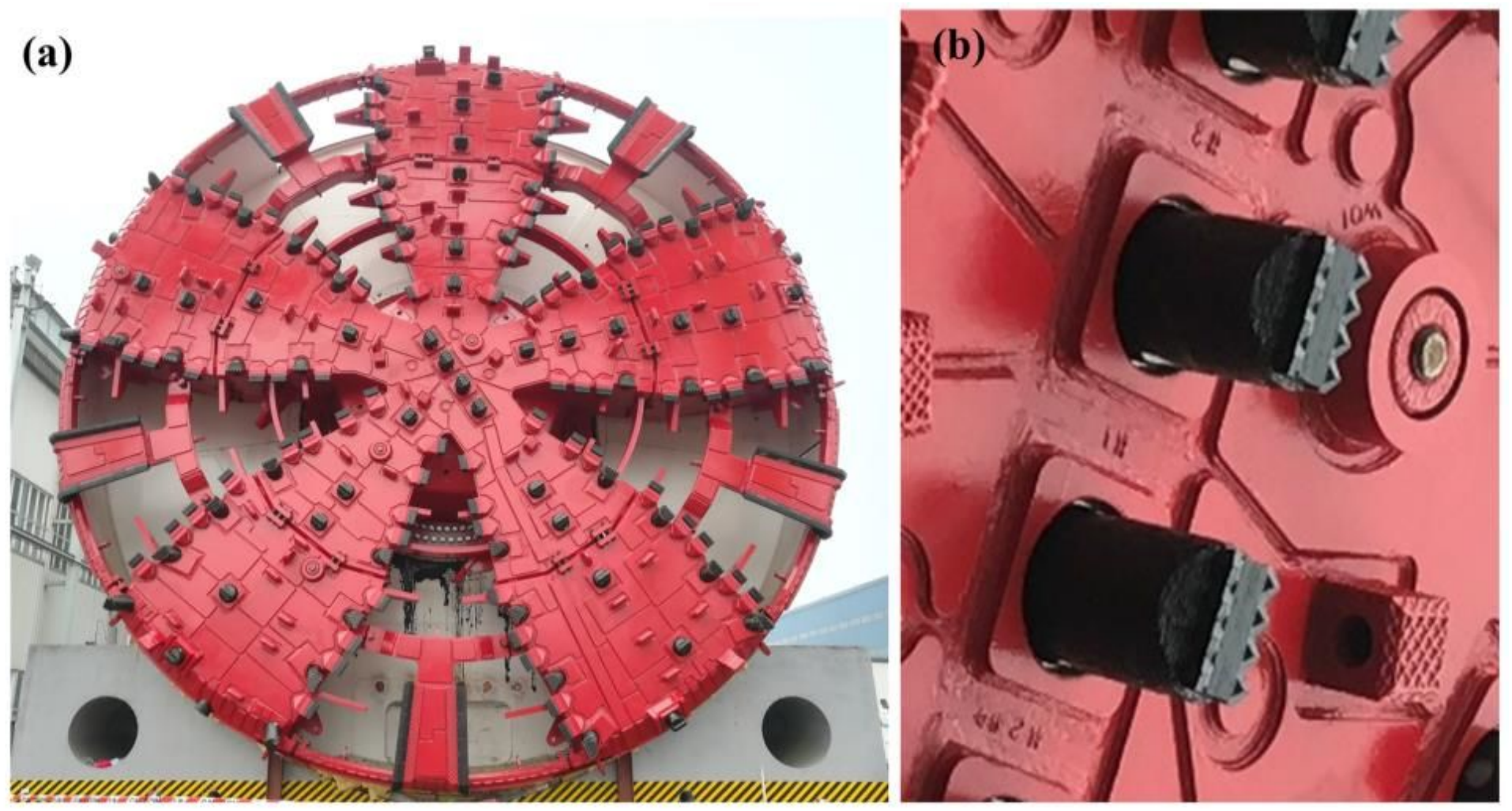

Figure 7

Cutterhead and cutter of the large-diameter slurry TBM: (a) cutterhead, (b) Normal pressure replaceable cutters.
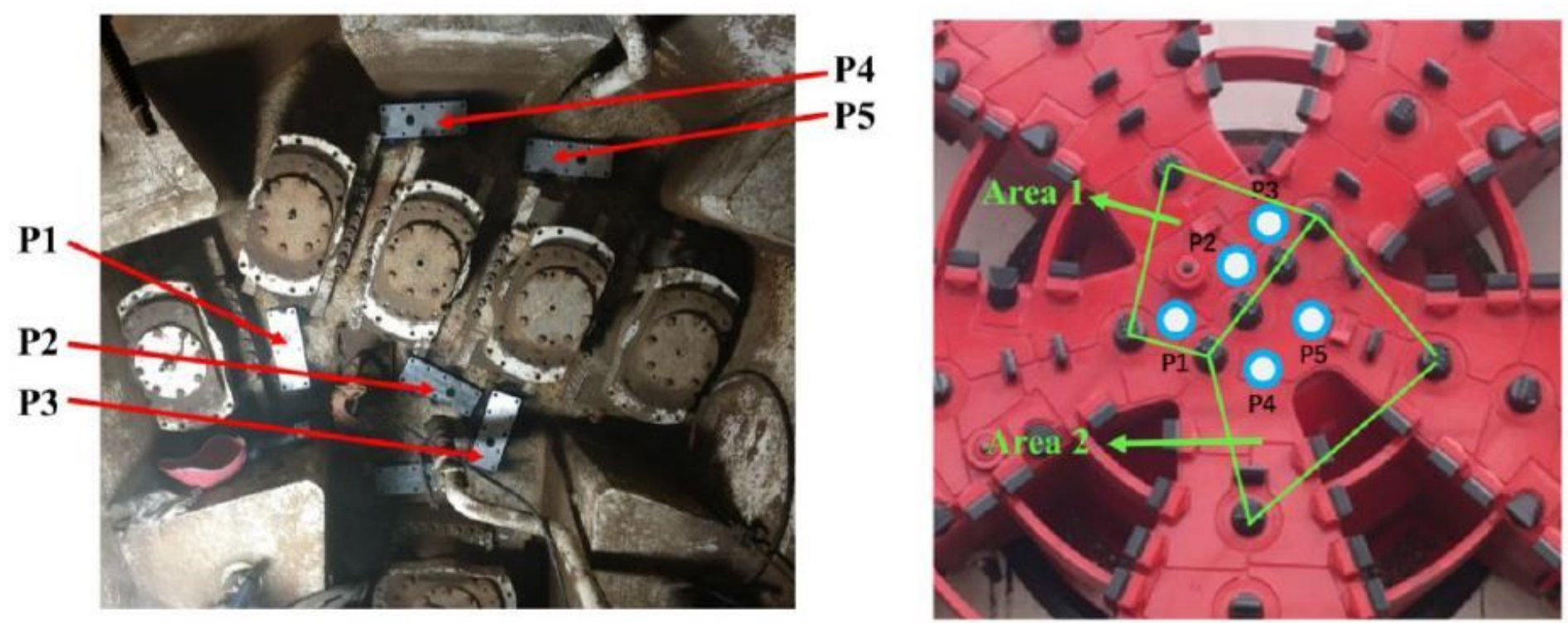

Figure 8

Images of sensors installed on the cutterhead 


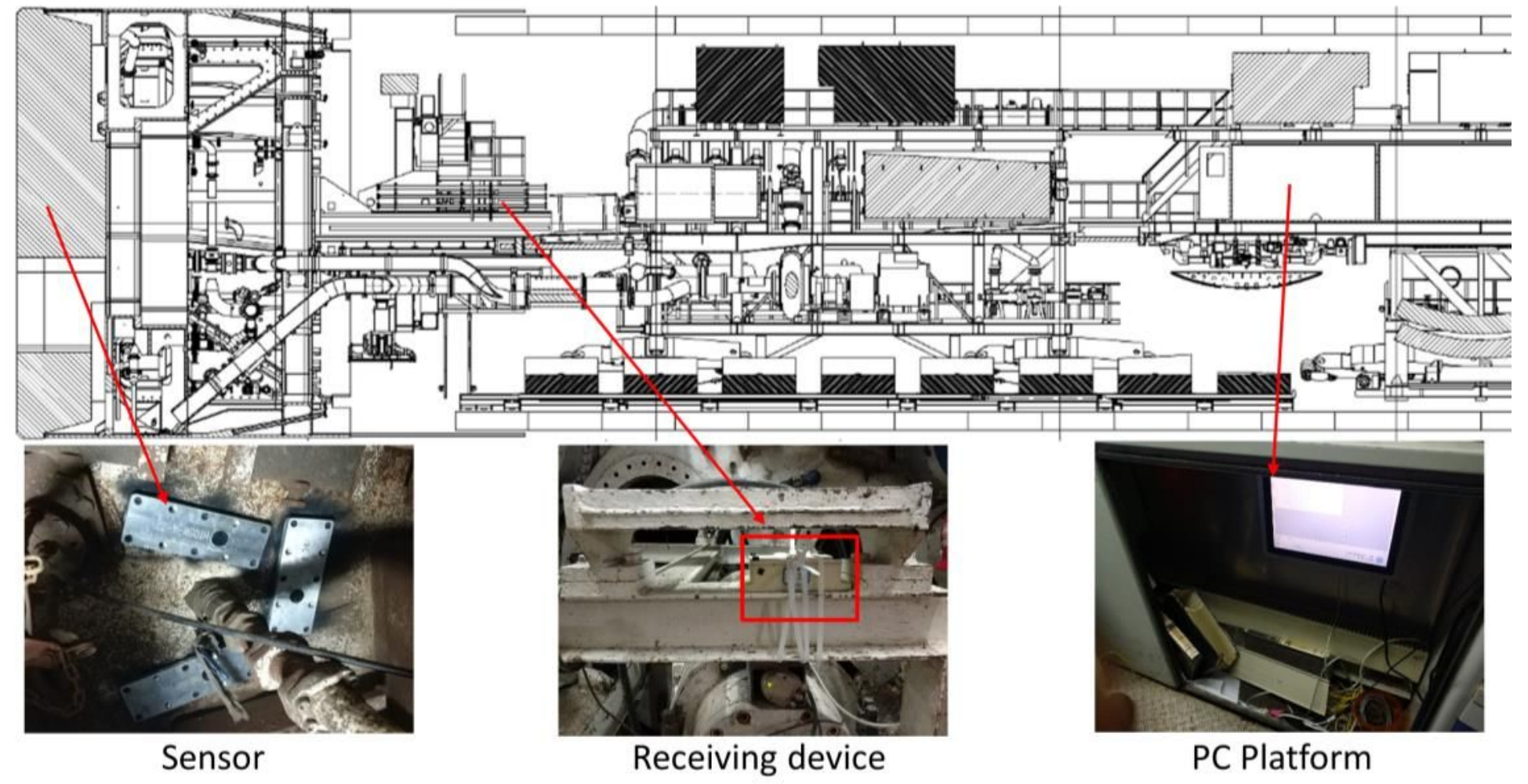

Figure 9

Installation position of monitoring system 


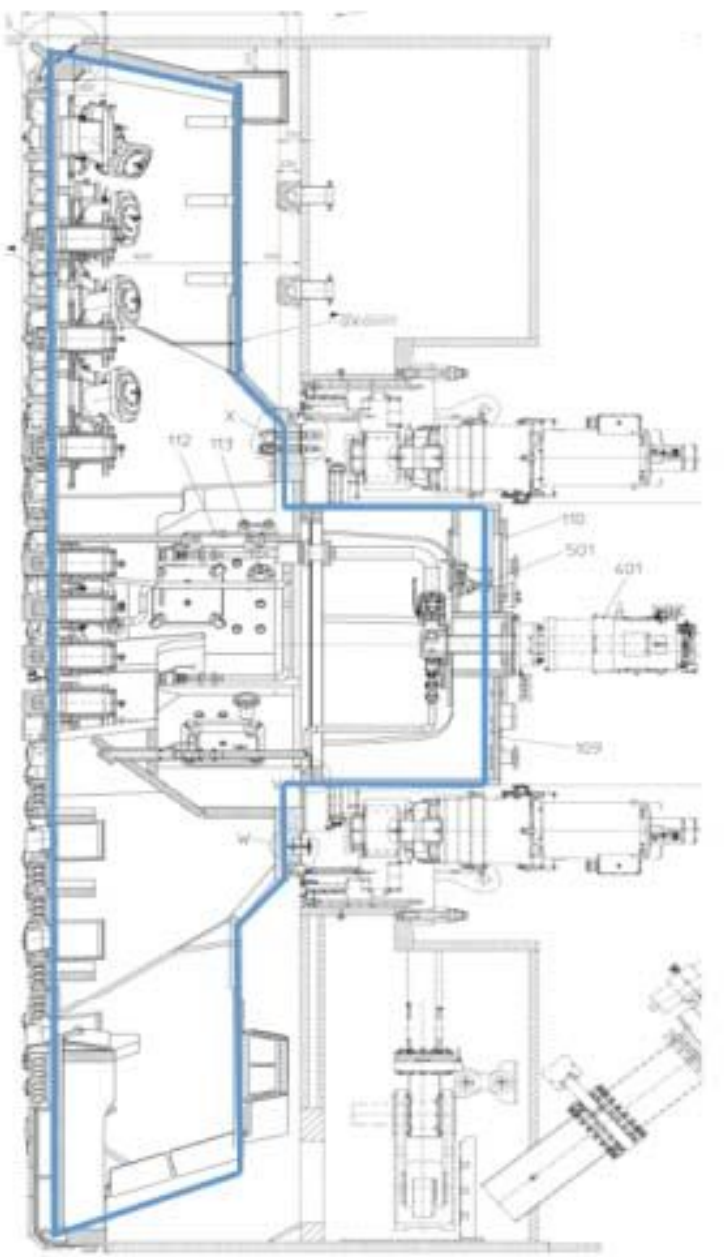

Cutter structure

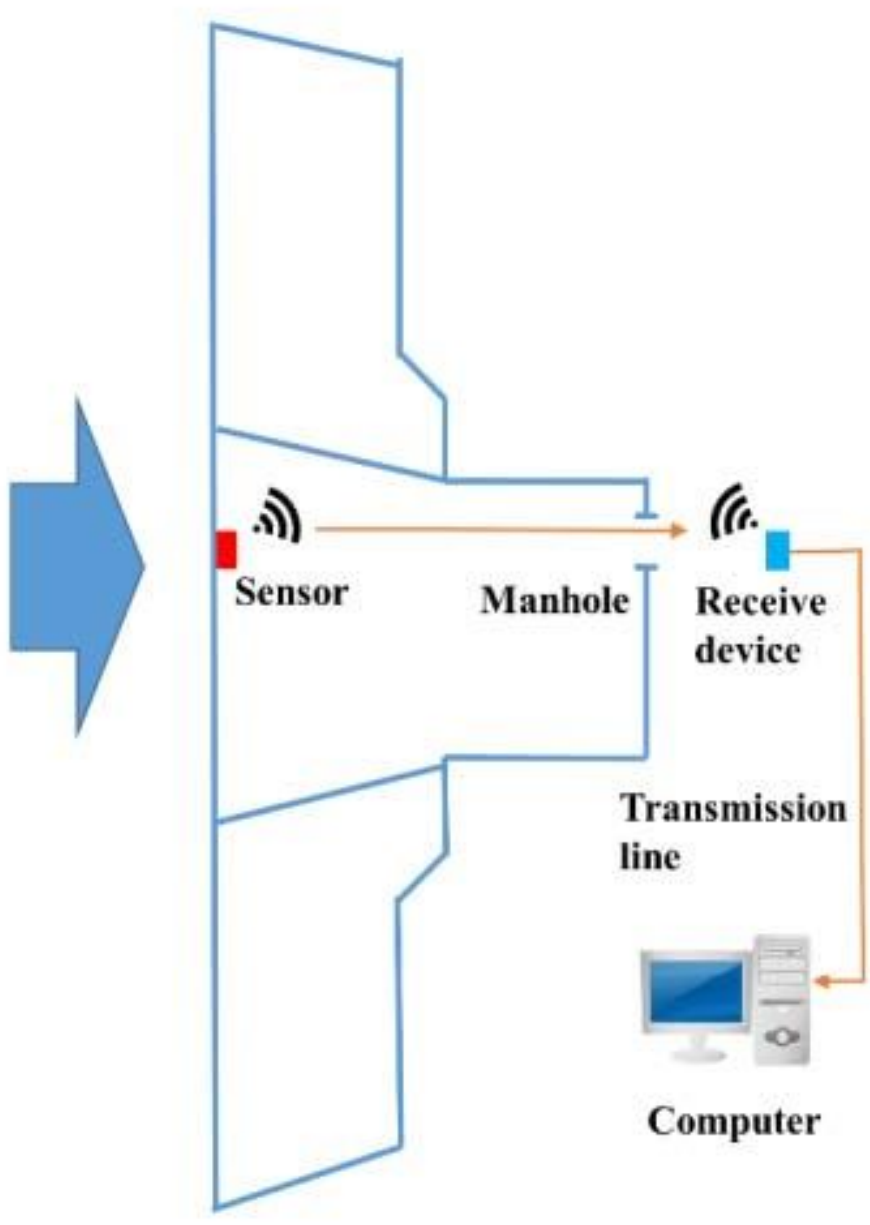

Simplified cutterhead

Figure 10

Cutterhead structure and signal transmission diagram 


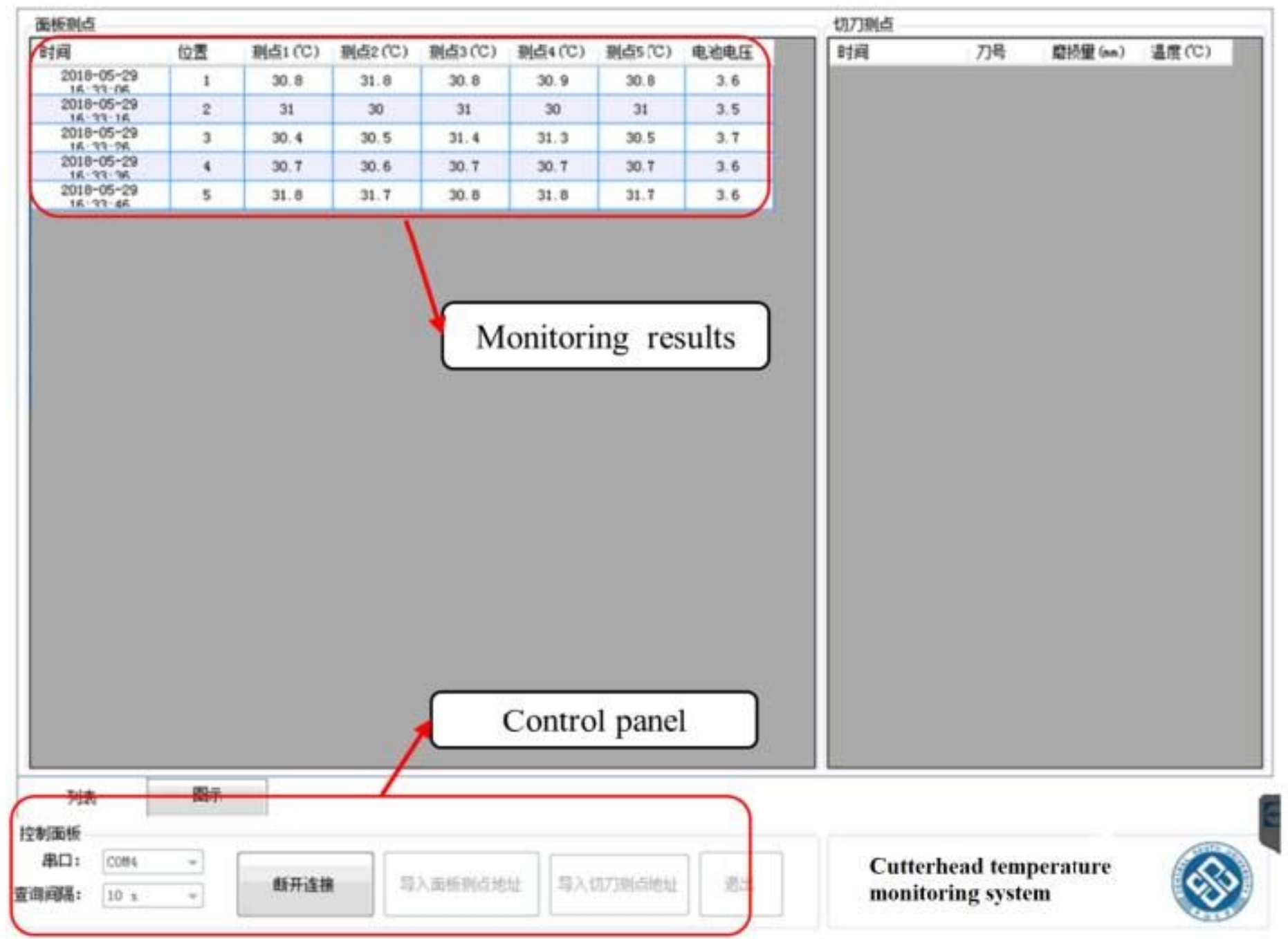

Figure 11

Self-developed temperature monitoring software 


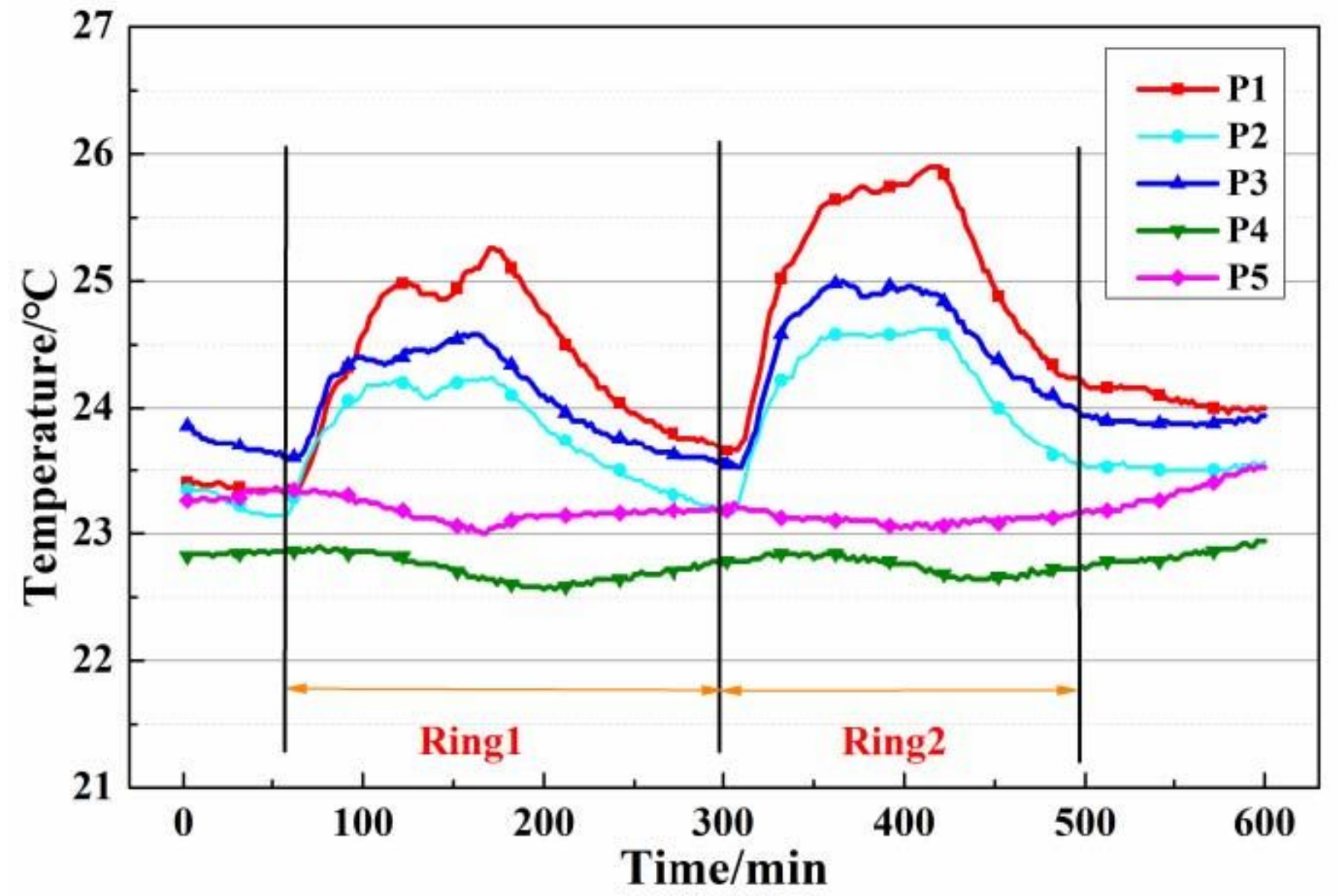

Figure 12

The temperature of cutterhead on April 10, 2018
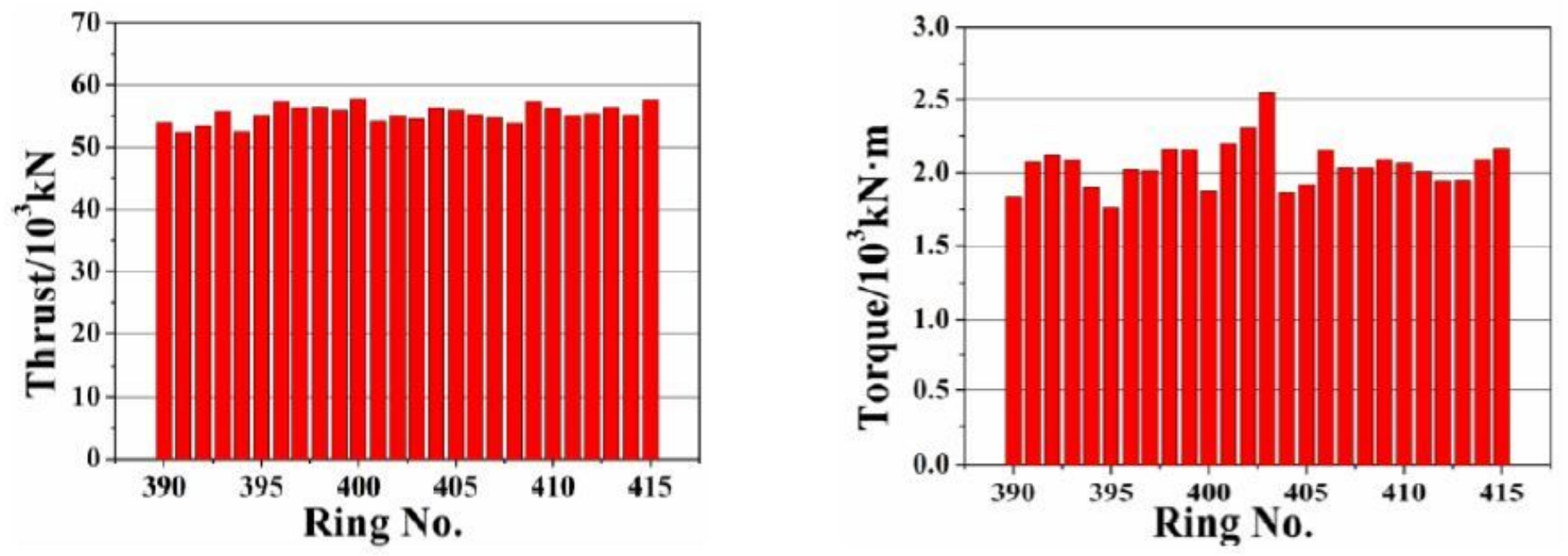

Figure 13

Thrust and Torque Statistics from April 9th to April 19th 


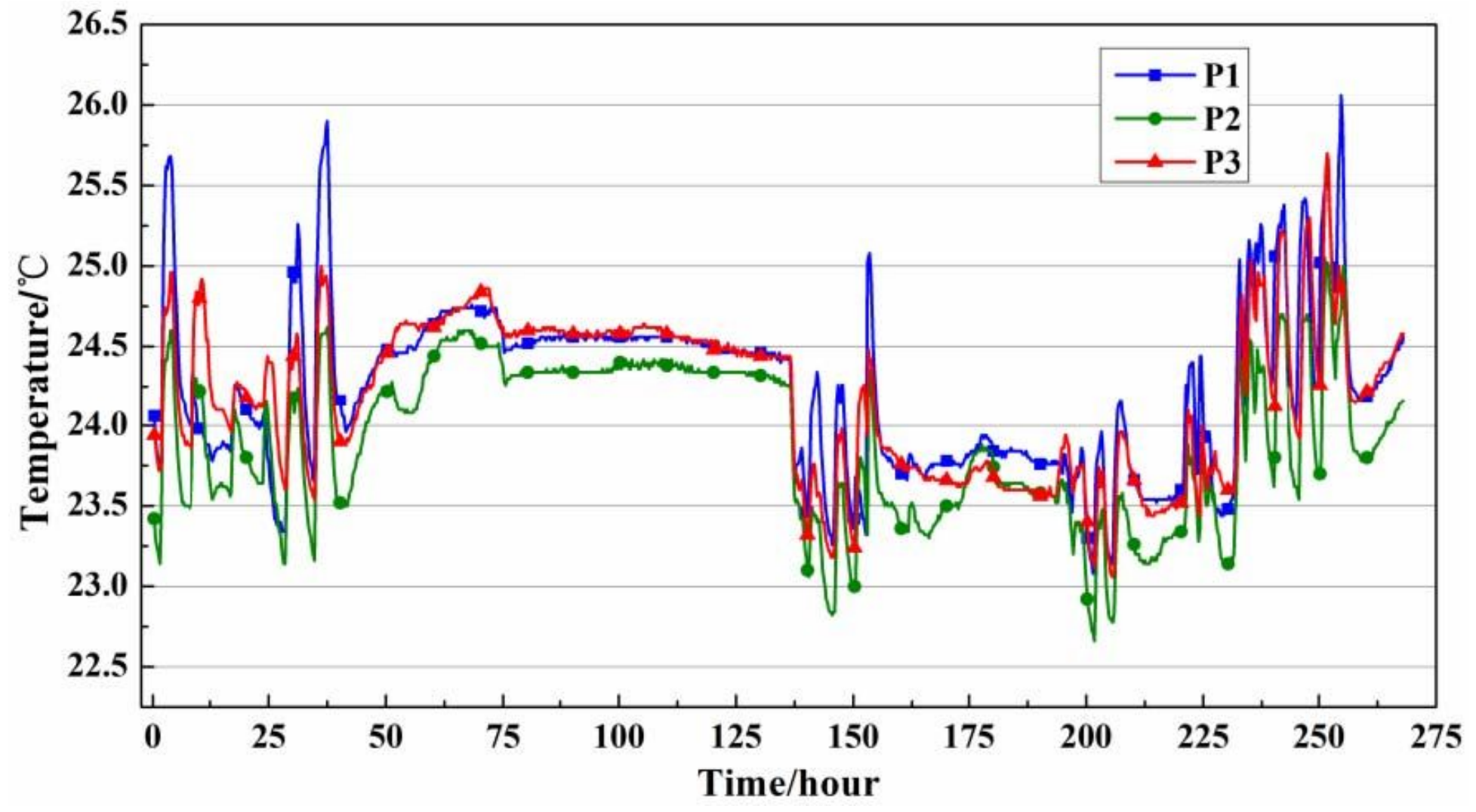

Figure 14

P1 P2 and P3 Temperature Data from April 9th to April 19th
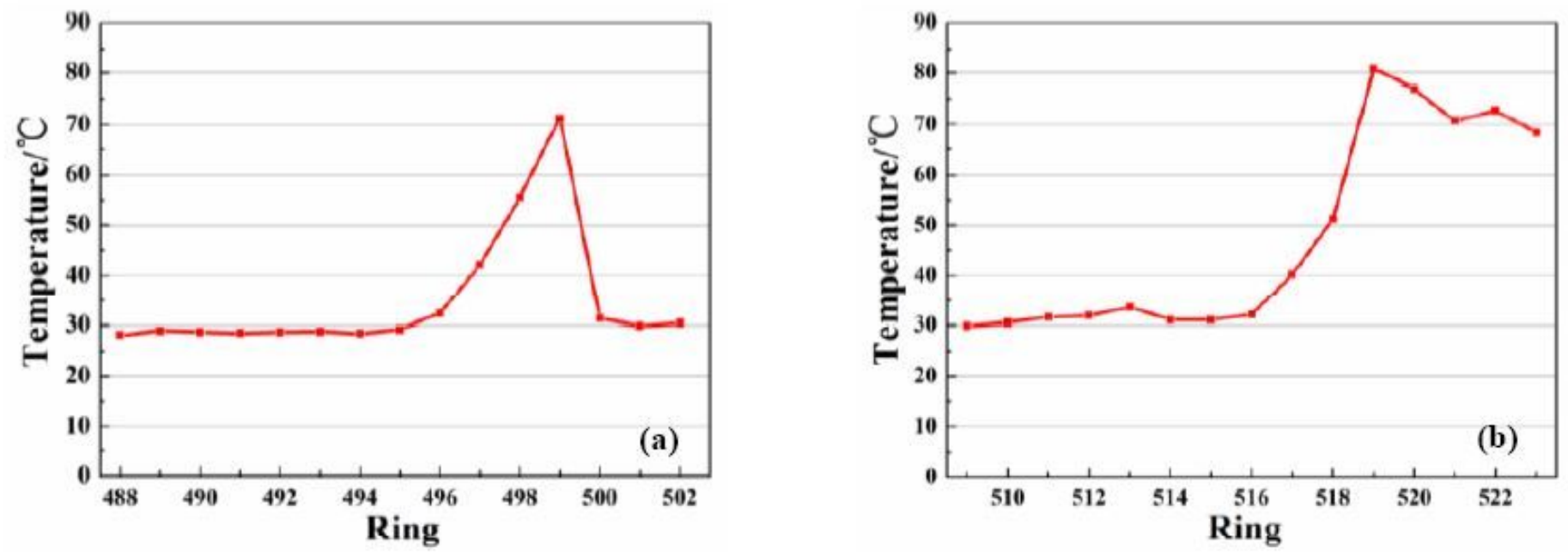

Figure 15

Temperature maximum: (a) First, (b) Second 

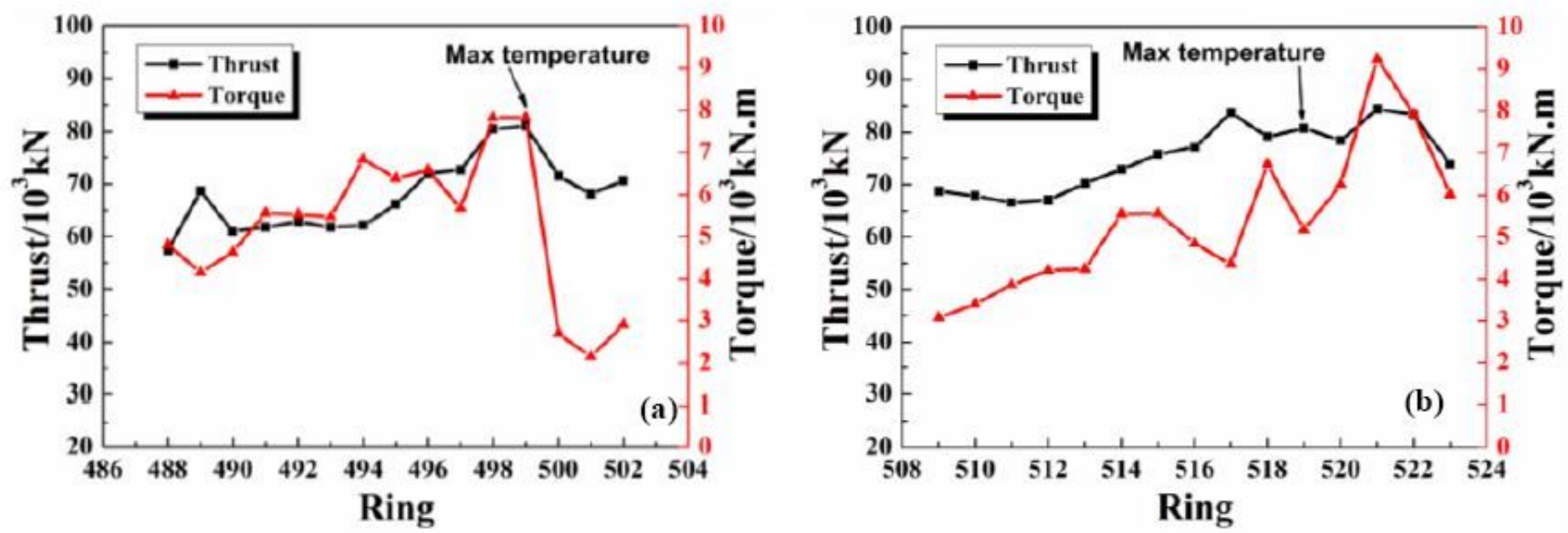

Figure 16

Average thrust and torque: (a) First, (b) Second
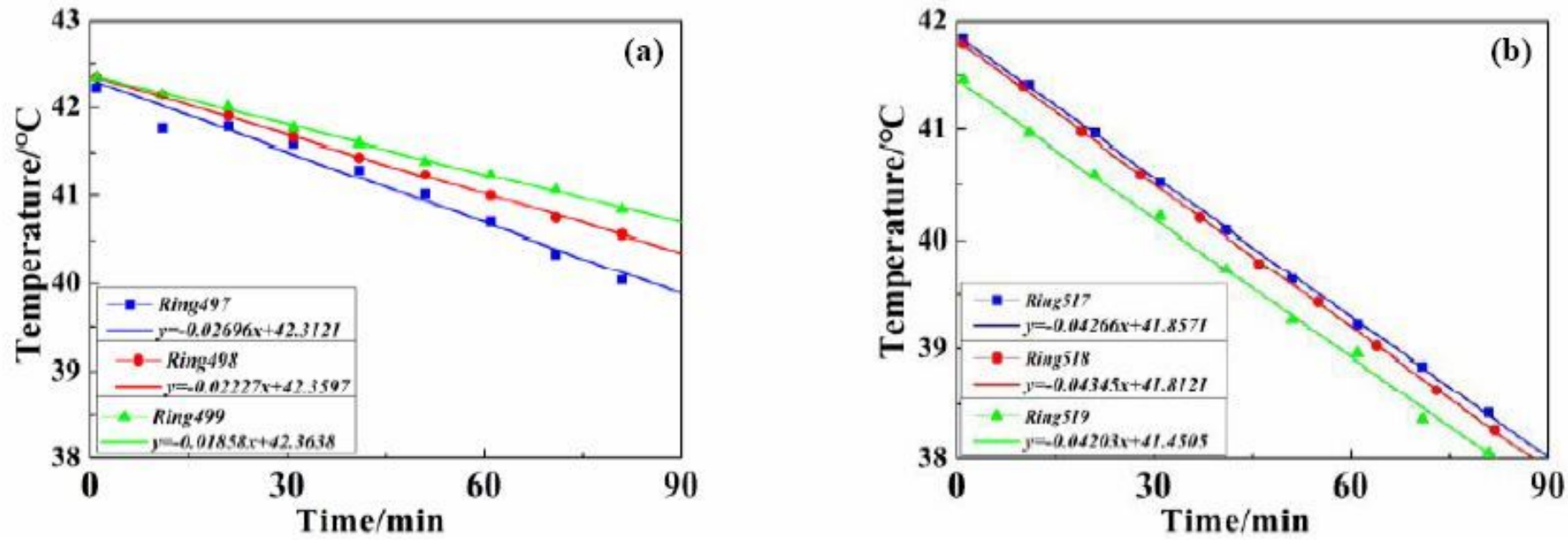

Figure 17

Temperature change regression curve: (a) First, (b) Second
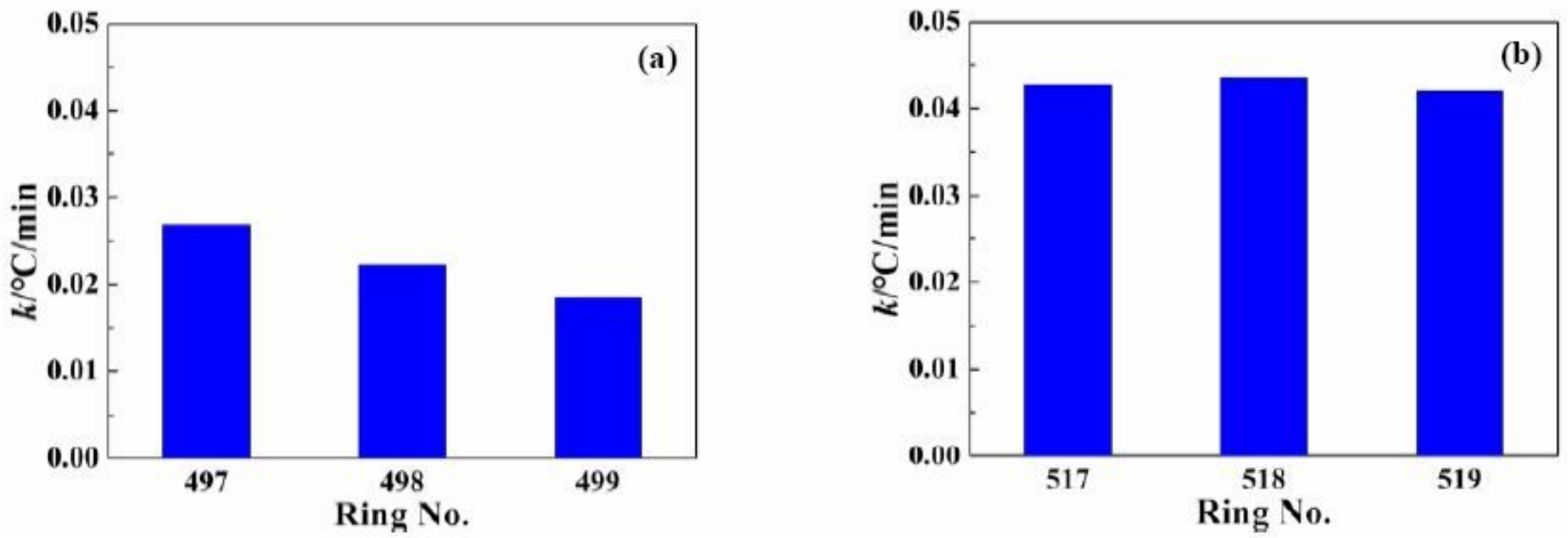
Figure 18

Cooling rate: (a) First, (b) Second
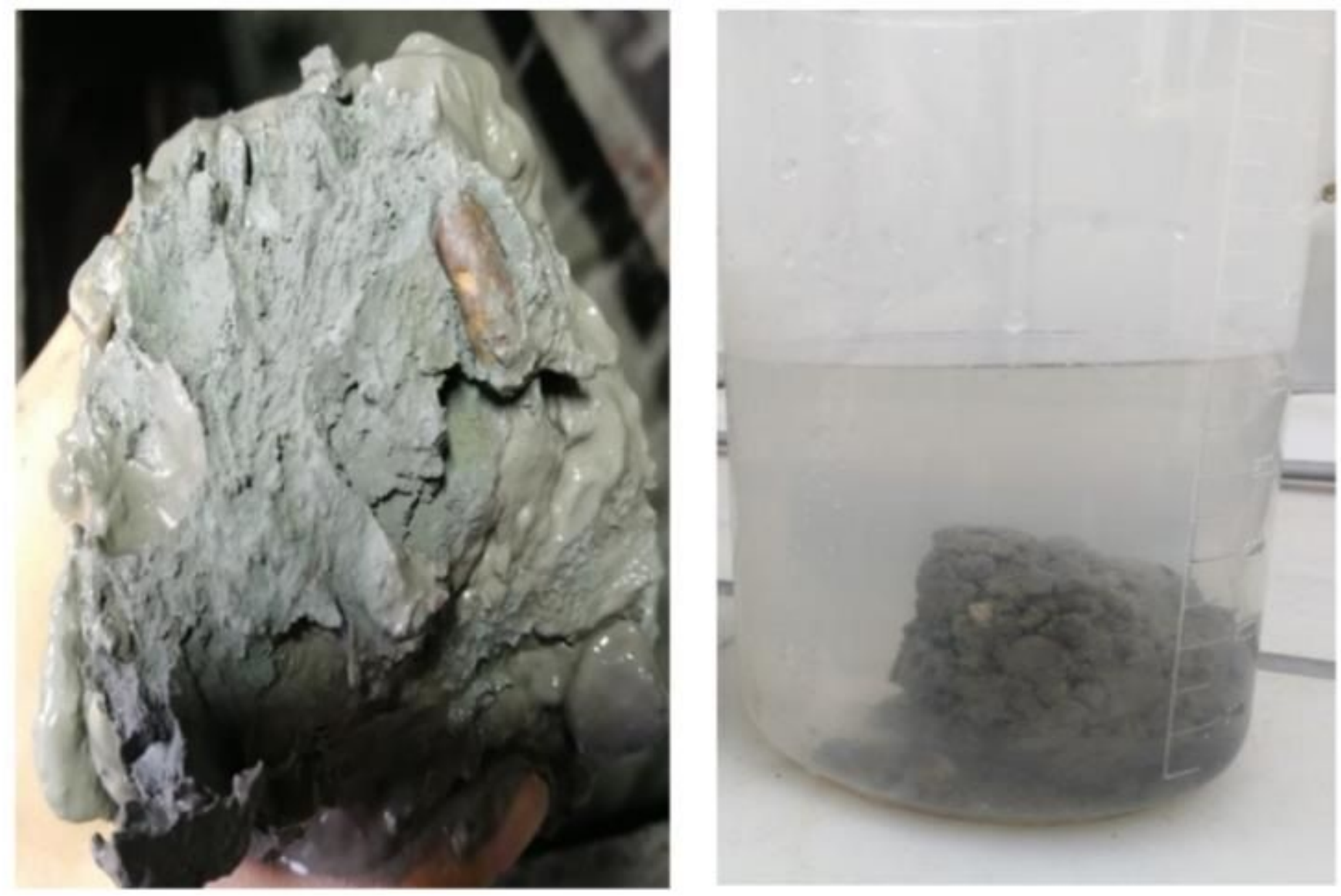

Figure 19

Mud cake sample was taken out form cutterhead 